OPEN ACCESS

Edited by:

César Nombela Arrieta, University of Zurich, Switzerland

Reviewed by:

Katherine Y. King,

Baylor College of Medicine,

United States

Roi Gazit,

Ben Gurion University

of the Negev, Israel

*Correspondence:

Hitoshi Takizawa

htakizawa@kumamoto-u.ac.jp

${ }^{\text {t}}$ These authors have contributed equally to this work

Specialty section: This article was submitted to Immunological Memory, a section of the journal

Frontiers in Immunology

Received: 20 July 2020 Accepted: 26 October 2020 Published: 24 November 2020

Citation: Sezaki M, Hayashi Y, Wang Y, Johansson A, Umemoto $T$ and

Takizawa H (2020) ImmunoModulation of Hematopoietic Stem and Progenitor Cells in Inflammation.

Front. Immunol. 11:585367. doi: 10.3389/fimmu.2020.585367

\section{Immuno-Modulation of Hematopoietic Stem and Progenitor Cells in Inflammation}

\author{
Maiko Sezaki ${ }^{1 \dagger}$, Yoshikazu Hayashi ${ }^{1,2,3 \dagger}$, Yuxin Wang ${ }^{1,4}$, Alban Johansson ${ }^{1,2}$, \\ Terumasa Umemoto ${ }^{2}$ and Hitoshi Takizawa ${ }^{1,5^{*}}$ \\ ${ }^{1}$ Laboratory of Stem Cell Stress, International Research Center for Medical Sciences (IRCMS), Kumamoto University, \\ Kumamoto, Japan, ${ }^{2}$ Laboratory of Hematopoietic Stem Cell Engineering, International Research Center for Medical Sciences \\ (IRCMS), Kumamoto University, Kumamoto, Japan, ${ }^{3}$ Division of Functional Structure, Department of Morphological Biology, \\ Fukuoka Dental College, Fukuoka, Japan, ${ }^{4}$ Department of Hematology, Zhujiang Hospital, Southern Medical University, \\ Guangzhou, China, ${ }^{5}$ Center for Metabolic Regulation of Healthy Aging, Kumamoto University, Kumamoto, Japan
}

Lifelong blood production is maintained by bone marrow (BM)-residing hematopoietic stem cells (HSCs) that are defined by two special properties: multipotency and selfrenewal. Since dysregulation of either may lead to a differentiation block or extensive proliferation causing dysplasia or neoplasia, the genomic integrity and cellular function of HSCs must be tightly controlled and preserved by cell-intrinsic programs and cell-extrinsic environmental factors of the BM. The BM had been long regarded an immune-privileged organ shielded from immune insults and inflammation, and was thereby assumed to provide HSCs and immune cells with a protective environment to ensure blood and immune homeostasis. Recently, accumulating evidence suggests that hemato-immune challenges such as autoimmunity, inflammation or infection elicit a broad spectrum of immunological reactions in the BM, and in turn, influence the function of HSCs and BM environmental cells. Moreover, in analogy with the emerging concept of "trained immunity", certain infection-associated stimuli are able to train HSCs and progenitors to produce mature immune cells with enhanced responsiveness to subsequent challenges, and in some cases, form an inflammatory or infectious memory in HSCs themselves. In this review, we will introduce recent findings on HSC and hematopoietic regulation upon exposure to various hemato-immune stimuli and discuss how these challenges can elicit either beneficial or detrimental outcomes on HSCs and the hemato-immune system, as well as their relevance to aging and hematologic malignancies.

Keywords: hematopoietic stem cells, BM environment, inflammation, infection, immune-memory

\section{CELLULAR HETEROGENEITY IN EARLY HEMATOPOIESIS AND THE BM NICHE IN STEADY STATE}

Lifelong replenishment of all mature blood and immune cells is sustained by a rare population of hematopoietic stem cells (HSCs) through a hierarchically organized lineage commitment program. In steady-state, the adult HSC pool is relatively quiescent but upon cell cycle entry, a stepwise specification of long-term reconstituting HSCs to progressively multi-, oligo- and uni-potent 
hematopoietic progenitors (HPCs) restricted to the myeloid, lymphoid, and megakaryocyte-erythroid lineages supply the total blood cell pool (1). This program shows flexibility and durability to sudden hematopoietic perturbations such as blood loss or inflammation and reflects strict control over HSC selfrenewal versus differentiation, as exhaustion or an imbalance in either will readily amount in hematopoietic failure and/or hematologic malignancies. The section will review current findings on HSC heterogeneity and its contribution toward steady-state hematopoiesis and briefly, cover essential concepts of the BM niche relevant later in the text for understanding the impact of a perturbed or stressed BM environment on HSCs.

The recent advancement in single-cell-based techniques and analysis (e.g., single-cell transplantation, RNA/ATACsequencing) has been revealing in terms of HSC biology in both native and stress hematopoiesis (2). The traditional roadmap of hematopoiesis, where HSCs were once assumed homogeneous with identical differentiation ability is currently being reassessed. The HSC population is in fact heterogeneous as clarified from single-cell transplantation and lineage-tracing experiments with certain HSC subsets being biased toward either myeloid or lymphoid lineages.

A large pool of multipotent progenitors (MPPs) rather than HSCs has been thought to drive steady-state hematopoiesis. Supportive of this are several publications that utilize lineagetracing of genetically-labeled HSCs and barcoding via transposon tagging $(3,4)$. In contrast, Sawai et al., report of Pdzk1ip1-GFP-labeled HSCs as the ultimate source of continuous lymphopoiesis and myelopoiesis under steady-state conditions, which can be accelerated by a systemic interferon response (5). Chapple et al., utilize two independent HSC tracers, Krt18 and Fgd5 to likewise support this model, and additionally report a robust HSC contribution toward platelet and myeloid lineages (6). Although with no lineage bias as described in the previous study, Lu et al., similarly claim all donor-derived HSC clones regenerate the blood homogeneously under homeostasis, while in perturbed or conditioned states, a small fraction of engrafted HSC clones will dominantly expand and exhibit lineage bias (7). While this issue remains unresolved, the heterogeneity of HSCs nonetheless adds an additional layer of complexity in understanding HSC biology and requires consideration when interpreting functional readouts of steadystate and stress hematopoiesis, including infection and inflammation.

In addition to the well-established HSC immunophenotypes, lineage $\mathrm{Sca}^{-}{ }^{+} \mathrm{c}-\mathrm{Kit}^{+}$(LSK), endothelial protein C (EPCR) (8), and the SLAM family proteins (9) used for the isolation of phenotypic hematopoietic stem and multipotent progenitors (HSPCs), others have been described to reflect HSC function by enriching for distinct lineage bias upon transplantation. Recently, Neogenin-1 (NEO1) was identified to distinguish $\mathrm{NEO}^{+}$HSCs primed toward myelopoiesis at the cost of lymphopoiesis from NEO1- HSCs that show a balanced differentiation into both myelopoiesis and lymphopoiesis (10). $\mathrm{NEO}^{+}{ }^{+} \mathrm{Hox} b 5^{+} \mathrm{HSCs}$ expand with age while $\mathrm{NEO}^{-}{ }^{-} \mathrm{Hox} b 5^{+} \mathrm{HSC}$ counts remain unchanged as in young mice. Additionally, in vWF-GFP reporter mice, the megakaryocytic gene involved in platelet aggregation encoding von Willebrand factor (vWF) (11) was found to be expressed in $\sim 60 \%$ of phenotypically defined HSCs (LSKCD $150^{+} \mathrm{CD} 48^{-} \mathrm{CD} 34^{-}$) with a higher expression of $\mathrm{Mpl}$, encoding the thrombopoietin (TPO) receptor essential for megakaryocyte (Mk) and platelet production (12). This plateletprimed HSC subset with myeloid bias gives rise to lymphoidbiased HSCs, and thus are considered higher up in the hierarchical tree (11). The deficiency of Mitofusin 2, a regulator for mitochondrial fusion and tethering to the endoplasmic reticulum, results in reduced differentiation potential toward the lymphoid lineages (13). Several reports claim that platelet-biased HSCs residing at the apex of the HSC hierarchy are a major contributor of daily platelet production $(14,15)$. Indeed, a population of stem-like Mkcommitted progenitors, primed but quiescent during steadystate and activated only during acute inflammation to replenish the depleted platelet pool has also been reported (16). Lineage skewing of HSCs toward platelets has been similarly observed in the BM of aged mice, where dysfunctional aged macrophages with an enhanced inflammatory signature fail to efficiently clear presiding apoptotic cells. The resulting increase in IL-1 $\beta$ is thought to induce the observed megakaryocytic HSC bias (17). Mks as a distinct lineage segregated from other hematopoietic lineages is so far implicated from several studies. HSC subtypes briefly noted here have been ably reviewed by Yamamoto et al., in which they discuss how emerging concepts of HSC heterogeneity presented via recent platelet and red blood cell lineage analyses may require a redefining of the "stemness" concept (18).

HSCs reside within the $\mathrm{BM}$ niche, a myriad of cellular, molecular and physical components of the BM microenvironment that maintain HSCs through the release of certain niche factors $(19,20)$. The perivascular niche has been well-described and is comprised of endothelial cells (ECs) and CXCL12 abundant reticular (CAR) cells, leptin receptor $(\mathrm{LepR})^{+}$cells, and nestin ${ }^{+}$ cells, with the latter three showing considerable overlap and high expression levels of stem cell factor (SCF) and CXCL12. Niche constituents are crucial in regulating HSC identity as demonstrated by several deletion studies. For example, SCF deletion in LepR ${ }^{+}$cells and ECs eliminates quiescent and transplantable HSCs from the BM (21). Depletion of Mks (22, 23) and periarteriolar $\mathrm{NG}^{+}$stromal cells (24) results in HSC proliferation and are likewise thought to promote HSC quiescence. Interestingly, lineage-biased HSCs appear to occupy distinct BM microenvironments. Recently, myeloidbiased $\mathrm{vWF}^{+}$HSCs were found to be enriched in Mk niches, while lymphoid-biased $\mathrm{vWF}^{-}$HSCs were situated near quiescence-regulating arteriolar niches (25). Similar to HSCs, niche components are heterogeneous and form complex microenvironments with multiple inputs from cellular constituents. Together, a combination of cells coordinates the maintenance of the hematopoietic system both during steadystate and under perturbed situations. 


\section{INFLAMMATION-STRESSED EARLY HEMATOPOIESIS}

Inflammation is the physiological reaction of the body to tissue injury or foreign insult and triggers a protective response involving blood and immune cells, vessels, and various molecular mediators. This is best illustrated in the case of infection; immune cells at local sites are activated through self or non-self-antigen recognition, and subsequent waves of innate and acquired immunity are coordinated to ensure host defense (26). In contrast to secondary lymphoid organs primarily tasked with immune activation, primary lymphoid organs including the $\mathrm{BM}$ had been long regarded immune-privileged with only minor exposure to the immune response. BM-residing HSCs and memory immune cells were thus assumed exempt from immune insults that can cause cell exhaustion or death, and reserved for prospective life-threatening invasions. HSCs were considered safely shielded in a dormant state through transcriptional and epigenetic regulators and their role in the initiation and resolution of inflammatory insults was presumed minimal.

Recent findings however highlight the dynamic response of HSCs toward inflammation. HSCs directly sense inflammation through their extracellular and intracellular receptors, rapidly lose quiescence and proliferate in response to an external milieu of inflammatory factors and infectious agents. Common inflammatory signals reported to impact primitive hematopoiesis include interferon (IFN)- $\alpha$ (27-29), IFN- $\gamma(30,31)$, tumor necrosis factor (TNF)- $\alpha$ (32), transforming growth factor (TGF)- $\beta$ (33), interleukin (IL)-1 (34), IL-6 $(35,36)$, and macrophage colony-stimulating factor (M-CSF) (37); infectious agents include pathogen-associated molecular patterns (PAMPs) derived from microbes and dangerassociated molecular patterns (DAMPs), both of which are recognized by pattern recognition receptors (PRRs). The activation of respective downstream signaling pathways in HSCs may result in their mobilization, proliferation, or differentiation to boost immune cell production $(38,39)$. Infection restricted to peripheral tissues/organs is primarily dealt with by immune cells at local sites that will get activated, consumed, and ultimately replenished by HSPCs (Figure 1). In the case of a systemic microbial spread due to severe infection or sepsis, HSPCs in the $\mathrm{BM}$ are activated to proliferate and drive myelopoiesis at the expense of lymphopoiesis. This is known as emergency myelopoiesis and involves the de novo generation and release of immature and mature neutrophils from the $\operatorname{BM}(38,40)$.

Inflammatory cytokines are major regulators of stress hematopoiesis (39) (Table 1). Essers et al., reported that IFN- $\alpha$ produced by plasmacytoid dendritic cells (DCs) upon TLR9 activation (49) activated dormant HSCs and caused their entry into the cell cycle. During chemotherapy, the proliferative capacity of HSCs is likewise enhanced upon stimulation with IFN- $\alpha$. The proliferative stress ensued with 5 -fluorouracil (5-FU) treatment caused a profound reduction of WT HSCs, while IFNR $\alpha^{-1-}$ HSCs were mostly unaffected (27). IFN- $\gamma$ upregulation during Mycobacterium avium infection similarly activated HSCs and resulted in their increased cycling and proliferation (30). However, the effect of IFNs on HSCs can be diverse, as described in the case of the tick-borne pathogen Ehrlichia infection, where a robust production of IFN $\alpha / \beta$ impaired hematopoiesis through HSPC depletion and enforced HSPC quiescence (50). IL-1 produced by several cell types such as macrophages, ECs, and epithelial cells (51) directly stimulated HSCs and skewed their differentiation potential toward myeloid lineages through activation of PU.1, a transcription factor regulating the myeloid differentiation program (34). Likewise, upon LPS challenge, M-CSF secreted from ECs, macrophages, or fibroblasts was found to affect PU.1, and HSCs with higher PU.1 levels were primed toward myeloid differentiation (37). TNF- $\alpha$ mainly secreted by macrophages, $\mathrm{T}$ cells, and natural killer cells (52) promotes HSC survival and simultaneously, their myeloid differentiation via an NF-KB-PU.1-dependent mechanism (32). An alternative pathway in response to bacterial infection, driven by intermediate lineage-committed HPCs via osteoblast-derived IL-7, which is a crucial cytokine for lymphopoiesis has also been reported (48).

The effects of transient cytokine stimulation on HSC regulation is overall beneficial in fighting infection, but can also be detrimental when sustained by impairing HSC function as reported in the cases of chronic Mycobacterium avium infection (53), IFN- $\alpha$ (27) and LPS challenges (54), and IL-1 receptor stimulation (34). These detrimental effects may stem from the accumulation of DNA damage and double-strand breaks induced by various HSC activators (55). While the TGF- $\beta$ presented by non-myelin Schwann cells is essential for steady-state HSC maintenance (33), continuous TGF- $\beta$ stimulation in vitro appears to reduce HSC cell division and suppress their reconstitution ability (56). Interestingly, the proliferation of lymphoid-biased HSCs but not myeloid-biased HSCs, as defined by the Hoechst dye efflux efficiency or "side population" was suppressed (57). Upregulation of TGF- $\beta$ was found upon Trypanosoma cruzi infection (58), which suggests chronic infection may also differentially impact the function of HSCs. Collectively, these findings illustrate how HSCs respond to various cytokine stimulations by adjusting their proliferative capacity as well as their differentiation program. The duration and/or magnitude of the stimulation are possible determinants for the cellular fate of HSCs (i.e., self-renewal, differentiation, or apoptosis).

Toll-like receptors (TLRs) are a family of transmembrane receptors that serve as the first-line innate immune sensor for a variety of infection-derived PAMPs and DAMPs (59). The TLRs primarily expressed on HSPCs are TLR2 and TLR4; both bind to bacterial ligands and induce their myeloid differentiation (60). Lymph-duct circulating HSPCs also express TLRs and differentiate into myeloid cells upon their ligation (61), indicating that TLR expression may serve as a means of immuno-surveillance, to sense infection at local sites and increase hematopoietic production upon need. Alternatively, the expression of bacteria-sensing receptors on HSPCs evolved to deal with life-threatening infections in the devastating case innate immune cells ever fail in combat and systemic bacterial infiltration follows. A proof-of-principle study involved an acute challenge with lipopolysaccharide (LPS), a gramnegative bacterial component recognized by TLR4, and subsequent activation of quiescent HSCs to proliferate and differentiate into 


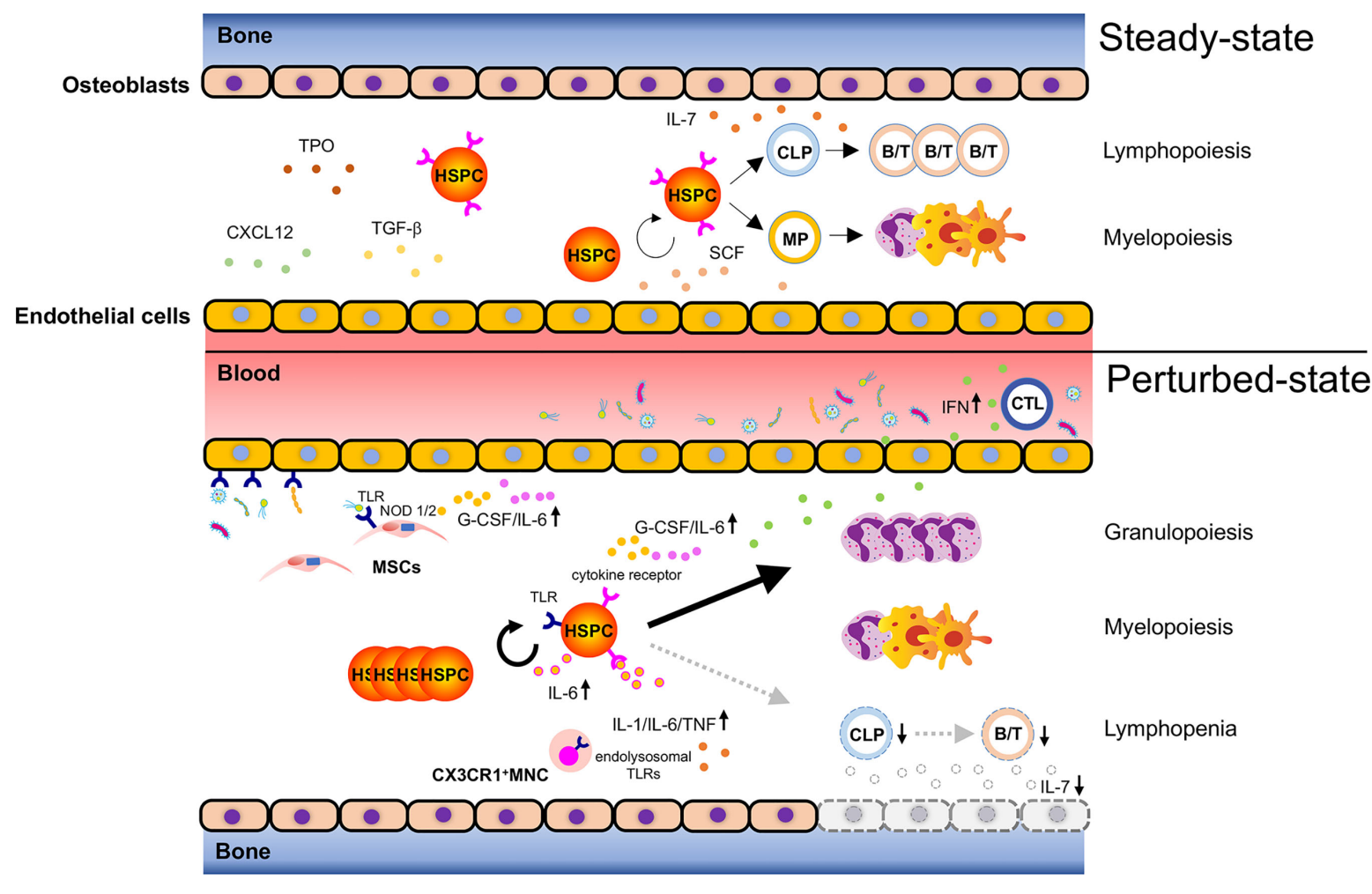

FIGURE 1 | Bacteria-induced activation of HSPCs. Steady-state hematopoiesis (upper): Hematopoietic stem and progenitor cells (HSPCs) self-renew and differentiate into myeloid progenitors (MPs) and common lymphoid progenitors (CLPS) to produce mature cells. The divisional manner of HSPCs toward either self-renewal or maturation (myelopoiesis/ymphopoiesis) is tightly controlled to sustain lifelong hematopoiesis. Hematopoiesis under infection (lower): Bacterial components reach the bone marrow (BM) via systemic blood circulation to activate pattern recognition receptors (PRRs) such as toll-like receptors (TLRs) expressed on HSPCs and promote their proliferation. Bacteriaassociated molecules reach the BM and can alternatively activate TLRs and NOD1/2 on endothelial cells or mesenchymal stromal cells (MSCs), leading to the secretion of inflammatory cytokines such as G-CSF and IL-6. These secreted cytokines promote granulopoiesis by acting on HSPCs. Cytotoxic T lymphocytes (CTLs) respond to bacterial infection and produce inflammatory cytokines such as IFNs, which migrate to the BM and activate corresponding receptors expressed on HSPCs. This results in reduced HSPC self-renewal and enhanced myelopoiesis. Severe bacterial infection such as sepsis rapidly ablates osteoblasts and induces lymphopenia due to lack of osteoblastderived IL-7. CX3CR1 ${ }^{+}$mononuclear cells (MNCs) sense bacteria-derived molecules such as bacterial DNA via endolysosomal TLRs and secrete the inflammatory cytokines, IL-1, IL-6, and TNF, which control the expansion of hematopoietic progenitors, and shift the hematopoietic program toward myelopoiesis. Taken together, bacterial challenges induce HSPC activation and myelopoiesis directly and indirectly at the expense of lymphopoiesis.

myeloid cells (60-62), while upon repetitive stimulation or chronic LPS challenge, HSC numbers increase but their reconstitution capacity decrease, somewhat recapitulating HSC aging $(54,63$, 64). The elicited downstream pathway appears bacterial speciesdependent, as Pseudomonas aeruginosa, a gram-negative bacteria induced HSC expansion through TLR4 (65), whereas Staphylococcus aureus, a gram-positive bacteria showed similar HSC expansion but through a TLR-independent pathway (66). Live Salmonella Typhimurium induced proliferative stress in HSCs, albeit through TLR4-dependent and -independent mechanisms (54). Besides bacteria, the fungus Candida albicans also expanded HSC-containing LSK cells of the BM via TLR2 and prompted their differentiation into granulocytes, monocytes, macrophages and DCs (67). Of note, upon TLR2 and TLR4 activation, HSPCs were also capable of secreting IL-6, a particularly important regulator of myelopoiesis in an auto- and paracrine manner (36). Finally, sustained increase in Sca- $1^{+}$HSPCs is a hallmark of bacterial and viral infections as described above, but also parasitic infections as well, as demonstrated in the malaria mouse model elicited by the Plasmodium berghei sporozoite, via direct HSC and progenitor proliferation (68).

Apart from invading pathogens, commensal bacteria or the microbiota can also regulate hematopoiesis. Microbiota depletion by antibiotics pretreatment induced atrophy of the thymus and spleen, and suppressed hematopoiesis in the BM by reducing HSC, MPP, and CLP numbers in a Stat1-dependent manner, and not via TLR signaling (69). Similarly, germ-free (GF) mice showed lower HSC, MPP, and CLP counts, and a selective functional defect in GMP and myelopoiesis (70). This phenotype was reversible and could be rescued with administration of the nucleotide-binding oligomerization domain (NOD) 1 ligand which activated mesenchymal stem cells (MSCs) to produce the inflammatory cytokines, IL-7, IL-6, TPO, SCF, and Flt-3. These results suggest peptidoglycan (PGN), the NOD1 ligand derived from the microbiota modulates daily hematopoiesis (71). Recently, CX3CR1 ${ }^{+}$monocytes were found 
TABLE 1 | The role of inflammatory cytokines or chemokines on steady-state and stress hematopoiesis.

\begin{tabular}{|c|c|c|c|}
\hline Cytokines & Which cells produce & Effect on HSC function & Reference \\
\hline SCF & Endothelial cell, MSC & HSC maintenance & Morrison Nature 2014 (20) \\
\hline CXCL12 & Endothelial cell, MSC, CAR cell & & \\
\hline Thrombopoietin (TPO) & Hepatocyte & & Decker Science 2018 (41) \\
\hline Transforming growth factor $\beta$ (TGF- $\beta$ ) & Schwann cell & & Yamazaki Cell 2011 (33) \\
\hline Fms-like kinase 3 (Flt-3) & Ubiquitous & Myeloid differentiation & Gabbianelli Blood 1995 (42) \\
\hline Interferon (IFN)- $\alpha$ & Plasmacytoid dendritic cell (DC) & $\begin{array}{l}\text { Impaired HSC reconstitution capacity } \\
\text { HSC exhaustion }\end{array}$ & $\begin{array}{l}\text { Esser Nature } 2009 \text { (27) } \\
\text { Sato Nat Med } 2009 \text { (28) } \\
\text { Pietras J Exp Med } 2014 \text { (29) }\end{array}$ \\
\hline $\mathrm{IFN}-\gamma$ & $\mathrm{T}$ cell & $\begin{array}{l}\text { Impaired HSC reconstitution capacity } \\
\text { Impaired HSC maintenance }\end{array}$ & $\begin{array}{l}\text { Baldridge Nature } 2010 \text { (30) } \\
\text { de Bruin Blood } 2013 \text { (31) }\end{array}$ \\
\hline $\begin{array}{l}\text { Granulocyte colony-stimulating factor } \\
\text { (G-CSF) }\end{array}$ & MSC, endothelial cell & Myeloid differentiation & $\begin{array}{l}\text { Boettcher J Immunol } 2012 \text { (43) } \\
\text { Boettcher Blood } 2014 \text { (44) }\end{array}$ \\
\hline Granulocyte-macrophage colony- & MSC, endothelial cell, macrophage, $T$ & & Weisbart Nature 1985 (45) \\
\hline stimulating factor (GM-CSF) & cell & & Shi Cell Research 2006 (46) \\
\hline $\begin{array}{l}\text { Macrophage colony-stimulating factor } \\
\text { (M-CSF) }\end{array}$ & Endothelial cell, macrophage, fibroblast & & Mossadegh-Keller Nature 2013 (37) \\
\hline Interleukin (IL-1) & $\begin{array}{l}\text { Macrophage, Endothelial cell } \\
\text { Epithelial cell }\end{array}$ & & Pietras Nat Cell Biol 2016 (34) \\
\hline Interleukin (IL-3) & $\mathrm{T}$ cell & & Suda J Cell Physiol 1985 (47) \\
\hline IL-6 & $\begin{array}{l}\text { Ubiquitous } \\
\text { HSPC (LSK) }\end{array}$ & & Zhao Cell Stem Cell 2014 (36) \\
\hline $\mathrm{IL}-7$ & Osteoblast & $\begin{array}{l}\text { Decrease of CLPs and induction of } \\
\text { lymphopenia }\end{array}$ & Terashima Immunity 2016 (48) \\
\hline TNF- $\alpha$ & Macrophage, T cell, natural killer cell & Myeloid differentiation & Yamashita Cell Stem Cell 2019 (32) \\
\hline
\end{tabular}

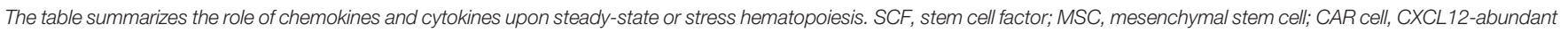
reticular cell; TNF, tumor necrosis factor.

to co-localize with HSPCs near blood vessels in the steady-state BM. These monocytes sensed commensal bacteria-derived molecules via their endolysosomal TLRs (TLR-3, -7, and -9) to produce tonic levels of the inflammatory cytokines, IL-1 $\beta$, IL-6, and TNF- $\alpha$ and control proliferation and myeloid differentiation of HSPCs (70). Thus, microbiota-derived molecules circulate the blood in both physiological and pathological conditions (72), reach the $\mathrm{BM}$, and are captured by specific hematopoietic and non-hematopoietic cells to fine-tune hematopoiesis.

\section{INFLAMMATION-STRESSED BM MICROENVIRONMENT}

Upon tissue insult, various BM cells have been reported to influence either HSCs or hematopoiesis, including adipocytes (73), endothelial vessels (74), osteocytes (75), neurons (76), macrophages (77) and Schwann cells (33) among others. The BM microenvironment has likewise been investigated at single-cell resolution during homeostasis and under stress hematopoiesis (78). The necessity of stromal cells for efficient HSC expansion and maintenance under perturbed conditions has become apparent from studies by several groups. Co-transplantation of $\mathrm{CD} 3^{+} \mathrm{CD} 105^{-} \mathrm{Scal}^{+} \mathrm{BM}$ stromal cells with donor-derived HSCs after irradiation resulted in efficient repairing of the damaged niche and improved HSC expansion (79). The transplanted stromal cells were localized within clusters of HSCs, indicating the efficient expansion of HSCs following their transplantation relied on local interactions with stromal cell progenitors. Guo et al., reported the importance of Jagged-2 induction in vascular niches after myeloablation for HSPC expansion and reacquisition of HSPC quiescence (80). Recently, a subset of apelin ${ }^{+}$ECs was shown to be critical not only for the maintenance of steady-state hematopoiesis but also after myeloablative injury. Apelin ${ }^{+}$ECs expanded substantially and mediated the regeneration of the vascular niche and subsequent hematopoietic reconstitution after BM transplantation via pleiotrophin (81). Thus, reciprocal interactions between the niche and HSCs are vital in determining efficient hematopoietic reconstitution under stressed conditions.

Infection-induced HSPC activation is mediated by a combination of direct and indirect pathways involving PRRs such as TLRs and NODs expressed on hematopoietic and non-hematopoietic cells (Tables 2 and 3). In particular, granulocyte-colony stimulating factor (G-CSF) secreted from TLR4-expressing ECs is essential and sufficient to activate GMPs and drive emergency myelopoiesis (43). Escherichia coli infection rapidly mobilized HSCs to the spleen via two innate immune sensors, nucleotide-binding oligomerization domain (NOD)-like receptor $1 / 2$ and TLR4, both of which are expressed on radio-resistant cells, presumably stromal cells. Their activation synergistically induced G-CSF secretion for efficient HSC mobilization and neutrophil differentiation (84). LPS challenge also drives vascular remodeling in the BM, proliferation of ECs and increase in their permeability, and accompanies HSPC proliferation and neutrophil mobilization from the BM (85). Del-1 is an extracellular matrix protein expressed by cellular components of the HSC niche, including ECs and CAR cells. Del-1 deficiency attenuated emergency myelopoiesis and HSPC expansion both in steady-state and in response to LPS and G-CSF injections (86). Intravital BM imaging revealed parasitic Trichinella spiralis infection dramatically increased HSC motility within the BM and their migration to other BM spaces (87). Parvovirus B19 caused 
TABLE 2 | Pattern recognition receptors expressed by hematopoietic cells that regulate steady-state and stress hematopoiesis.

\begin{tabular}{|c|c|c|c|c|c|c|}
\hline Receptors & Ligands & Cell type & Species & Signaling & Function & Reference \\
\hline \multirow[t]{2}{*}{ TLR2 } & Candida albicans & LSK (Lin ${ }^{-}$Sca- $\left.1^{+} \mathrm{C}-\mathrm{kit}^{+}\right)$ & Mouse & $\begin{array}{l}\text { TLR2-Myd88/ } \\
\text { Dectin1 }\end{array}$ & Differentiation into DCs & Yanez PLoS One 2011 (67) \\
\hline & Pam3CSK4 & $\begin{array}{l}\operatorname{Lin}^{-} \\
\mathrm{CD} 34^{+}\end{array}$ & $\begin{array}{l}\text { Mouse } \\
\text { Human }\end{array}$ & TLR2-ROS & $\begin{array}{l}\text { Differentiation into macrophages } \\
\text { with lower levels of inflammatory } \\
\text { cytokines }\end{array}$ & $\begin{array}{l}\text { Yanez Eur J Immunol } 2013 \\
\text { (82) }\end{array}$ \\
\hline TLR2/4/9 & $\begin{array}{l}\text { Pam3CSK } 4 \\
\text { LPS } \\
\text { CpG }\end{array}$ & $\begin{array}{l}\text { Common dendritic cell } \\
\text { progenitor (CDP) }\end{array}$ & Mouse & $\begin{array}{l}\text { CXCR4 down- } \\
\text { regulation and } \\
\text { CCR7 up- } \\
\text { regulation }\end{array}$ & $\begin{array}{l}\text { DC expansion in inflamed lymph } \\
\text { nodes and support of DC } \\
\text { homeostasis }\end{array}$ & Schmid Blood 2011 (83) \\
\hline \multirow[t]{4}{*}{ TLR4 } & $\begin{array}{l}\text { LPS of Pseudomonas } \\
\text { aeruginosa }\end{array}$ & LSK $\left(\right.$ Lin $^{-}$Sca- $\left.1^{+} \mathrm{C}-\mathrm{kit}^{+}\right)$ & Mouse & TLR4 & Dysfunctional HSC expansion & Rodriguez Blood 2009 (65) \\
\hline & LPS & HSC (CD150+CD48-LSK) & Mouse & TLR4 & $\begin{array}{l}\text { Increased HSC number but } \\
\text { decreased HSC reconstitution } \\
\text { potential }\end{array}$ & Esplin J Immunol 2011 (64) \\
\hline & LPS & HSC (CD150+CD48-LSK) & Mouse & TLR4-Id1 & $\begin{array}{l}\text { Increased HSC number but induced } \\
\text { HSC dysfunction }\end{array}$ & Zhao PLoS One 2013 (63) \\
\hline & $\begin{array}{l}\text { LPS } \\
\text { Salmonella } \\
\text { Typhimurium }\end{array}$ & $\begin{array}{l}\text { HSC } \\
\left(\mathrm{CD} 150^{+} \mathrm{CD} 135^{-} \mathrm{CD} 34^{-} \mathrm{CD} 48^{-}\right. \\
\mathrm{LSK} \\
\text { CD150+CD34-CD48-CD41- } \\
\text { LSK) }\end{array}$ & Mouse & $\begin{array}{l}\text { TLR4-TRIF- } \\
\text { ROS-p38 }\end{array}$ & $\begin{array}{l}\text { Proliferative stress-induced HSC } \\
\text { dysfunction }\end{array}$ & $\begin{array}{l}\text { Takizawa Cell Stem Cell } \\
2017(54)\end{array}$ \\
\hline TLR3/7/9 & bacterial DNA & $\mathrm{CX} 3 \mathrm{CR} 1^{+} \mathrm{MNC}$ & Mouse & $\mathrm{TLR} 3 / 7 / 9$ & $\begin{array}{l}\text { Inflammatory cytokine production by } \\
\mathrm{CX} 3 \mathrm{CR} 1^{+} \text {MNCs induced MPP } \\
\text { expansion and steady-state } \\
\text { myelopoiesis }\end{array}$ & Lee Blood 2019 (70) \\
\hline
\end{tabular}

The table summarizes the role of pattern recognition receptors expressed in hematopoietic cells upon steady-state or stress hematopoiesis. TLR, Toll-like receptor; DC, dendritic cell; Pam3CSK4, Pam3Cys-Ser-(Lys)4; ROS, reactive oxygen species; LPS, lipopolysaccharide; CCR, CC chemokine receptor; CXCR, CXC chemokine receptor; MNC, mononuclear cell; CX3CR1, CX3C chemokine receptor 1; HSC, hematopoietic stem cell; MPP, multipotent progenitor.

TABLE 3 | Pattern recognition receptors expressed by non-hematopoietic cells that regulate steady-state and stress hematopoiesis.

\begin{tabular}{|c|c|c|c|c|c|c|}
\hline Receptors & Ligands & Cell type & Signaling & Species & Function & Reference \\
\hline \multirow[t]{2}{*}{ TLR4 } & LPS & Non-hematopoietic cell & TLR4 not IL-1R & Mouse & G-CSF-mediated emergency myelopoiesis & $\begin{array}{l}\text { Boettcher J Immunol } \\
2012 \text { (43) }\end{array}$ \\
\hline & & Endothelial cell & TLR4-Myd88 & & & $\begin{array}{l}\text { Boettcher Blood } 2014 \\
\text { (44) }\end{array}$ \\
\hline TLR4 & LPS & Non-hematopoietic cell & G-CSF up-regulation and & Mouse & G-CSF-induced HSC mobilization to spleen & Burberry Cell Host \\
\hline NOD1/2 & PGN & & CXCL12 down-regulation & & & Microbe 2014 (84) \\
\hline NOD1 & PGN & MSC & NOD1 & Mouse & $\begin{array}{l}\text { Regulation of steady-state hematopoiesis via } \\
\text { cytokine production by MSCs }\end{array}$ & Iwamura Blood 2017 (71) \\
\hline
\end{tabular}

The table summarizes the role of pattern recognition receptors expressed in non-hematopoietic cells upon steady-state or stress hematopoiesis. TLR, Tol- like receptor; LPS, lipopolysaccharide; G-CSF, granulocyte-colony stimulating factor; NOD, Nucleotide-binding oligomerization domain-containing protein; PGN, peptidoglycan; MSC, mesenchymal stem cell.

transient erythroid aplasia by infecting MSCs and upregulating their expression of IL- 6 and TNF- $\alpha$ (88). Treatment with IFN- $\alpha$ or pI:C, a ligand for TLR3 and a mimetic of viral infection modulates hematopoiesis via hematopoietic- but also niche-expressed IFN- $\alpha$ receptor. Both challenges increased EC proliferation in the BM partly through vascular endothelial growth factor (VEGF) (89). Taken together, these findings indicate bacterial, viral, or parasitic infections can induce HSPC activation also through nichedependent pathways.

\section{CHEMOTHERAPY- AND IRRADIATION- INDUCED INFLAMMATION}

Similar to naturally occurring infections, quiescent HSCs are recruited to actively divide and regenerate the hematopoietic system in response to artificial BM ablating agents, such as irradiation or chemotherapy. Here, HSC activation is likely caused by a transient surplus of systemic cytokines that occur after irradiation- or chemotherapy-induced BM suppression. Cytokine levels in the serum or BM, including SCF and TPO were elevated due to their reduced consumption by surrounding hematopoietic cells $(90,91)$. Specifically, the elevation of TPO, SCF, IL-3, FLT3, and CXCL12 after lethal irradiation protected HSPCs from apoptosis and improved the survival of irradiated mice (92). Other cytokines of note include TNF- $\alpha$, IL-1 $\beta$, and IL6 detected in the serum (93) and additionally IL- $1 \alpha$, IFN- $\alpha / \beta$, and GM-CSF in several cell types (94). Thus, not only local but also systemic cytokine levels determine the fate of HSCs post BM suppression.

Low mitochondrial membrane potential in steady-state HSCs is maintained by extracellular adenosine supplied by surrounding 
myeloid progenitors, known to possess an anti-inflammatory effect (95). After 5-FU administration, the ablation of surrounding myeloid progenitors will result in low adenosine and consequently high mitochondrial activity and reactive oxygen species (ROS) production in HSCs. This is essential for initiating HSC cellular division and hematopoietic repopulation (95), but contradicts with a previous study claiming the negative regulation of ROS on HSC maintenance (96), and high mitochondrial membrane potential with reduced hematopoietic repopulating ability in steady-state and IFN- $\alpha$-stimulated HSCs (97). Thus, the response of activated HSCs toward ROS is contextdependent and markedly differs from quiescent HSCs in steadystate. This is further evidenced in HSCs with enhanced mitochondrial activity and ROS levels possessing more potential for rapid regeneration of $\mathrm{Mks}$ and platelets after 5FU administration (98). Here, TPO injection enhanced mitochondrial activity in HSCs and primed their differentiation toward the Mk-lineage. Not only are Mks a rich source of inflammatory cytokines and chemokines released upon acute injury and inflammation, but they can also cooperate with neutrophils to trap invading pathogens $(99,100)$. Among the cytokines, C-X-C motif ligand 4 (CXCL4) (22) has been reported to increase hematopoietic recovery of 5-FU-induced $\mathrm{BM}$ suppression (101). Fibroblast growth factor 1 (FGF1) supplied by Mks also contributed to the expansion of HSCs after chemotherapeutic stress by counteracting TGF- $\beta$ inhibitory signaling (23). Furthermore, Mks help expand endosteal nicheresiding osteoblasts after irradiation through the secretion of platelet-derived growth factor (PDGF)-BB, and thereby support hematopoietic recovery (102). Taken together, HSC-generated Mks and platelets serve as an essential source of hematopoietic recovery factors that regulate HSCs directly and indirectly through the BM niche.

Since BM injury induced by irradiation or chemotherapy affects not only hematopoietic cells but also non-hematopoietic cells within the $\mathrm{BM}$, the reconstruction of the niche may well be key for a successful hematopoietic recovery. Angiopoietin-1 supplied from osteoblasts protects HSCs from BM suppression (103). Of note, angiopoietin-1 secreted by LepR ${ }^{+}$stromal cells can also negatively influence hematopoietic regeneration after irradiation (104). Adipocytes are an additional BM niche component found to proliferate extensively after irradiation or chemotherapy to promote hematopoietic regeneration by supplying SCF to HSCs, which under normal circumstances is provided by LepR ${ }^{+}$cells and ECs (73). Other factors besides SCF, including adiponectin (105) and leptin (indirectly via adipogenesis) can support HSC proliferation after irradiation (106). Moreover, a radio-resistant $\mathrm{CD} 105^{-} \mathrm{CD}^{+} 3^{+} \mathrm{NGFR}^{\mathrm{hi}}$ stromal subset expressing high levels of hematopoietic cytokines was found to support hematopoietic regeneration after irradiation (107). Co-transplantation of MSCs overexpressing PDGF- $\beta$ improved the engraftment of transplanted HSCs via enhanced HSC self-renewal and expansion (108). Niche regeneration precedes HSC regeneration after irradiation, and by enlarging the niche pool, a better environment to facilitate HSC engraftment can be achieved. Thus, BM niches are also affected by BM injury, and these alterations contribute to the regeneration of the hematopoietic system.

Since irradiation or chemotherapy damages the DNA of hematopoietic cells, molecules relevant for the DNA damage and repair machinery play a key role in hematopoietic recovery. For instance, histone deacetylase 8 (HDAC8), which modulates p53 activation contributes to HSC survival by blocking apoptosis. HDAC8-deficiency showed hematopoietic failure and increased lethality after the administration of 5-FU (109). Similarly, deficiency of the growth arrest and DNA-damage-inducible protein (Gadd45a), a key tumor suppressor showed efficient recovery of the hematopoietic system through enhanced proliferation of HSPCs, although at the expense of their genomic integrity (110). These phenotypes are attributed to a decrease in HSPC apoptosis due to a greater resistance to DNA damage. Additionally, deficiency of Rap1, a member of the shelterin proteins decreased double-strand DNA break repair through the non-homologous end-joining pathway, and consequently HSC survival after irradiation or chemotherapy (111). Thus, the ability of HSCs to respond efficiently to DNA damage is one of several factors that determines HSC survival under stress conditions. However, since excess resistance to DNA damage will increase the risk for pathogenesis, particularly in the case of Fanconi anemia (55) and leukemogenesis (110), an appropriate balance is required for a healthy hematopoietic recovery.

After BM injury, HSCs and their niches respond to a damaged $\mathrm{BM}$ environment by calling for an alternate response compared to steady-state conditions, which may continuously adjust until a return to quiescence. These serial changes may well dictate the appropriate and balanced supply of stem cells and differentiated cells, and the efficient regeneration of the hemato-immune system and BM niche. Further studies are needed to clarify such possibilities.

\section{IMMUNE-MEMORY IN HSPCs}

Host immune responses can be divided into a rapidly reacting innate response that is relatively non-specific, and a slowly developing adaptive response that is highly specific to the antigens of invading pathogens. After clearance of an infection, the latter can form a type of immunological memory, ensuring a swift and robust response against future infections and lifelong immune protection. The concept of immunological memory was restricted to adaptive immunity but has since been extended to include innate immunity in the last decade. Indeed, various innate immune cells (i.e., monocytes, macrophages, natural killer (NK) cells) show a long-term adaptation of increased reactivity upon secondary stimulation, a state termed trained immunity (112). Epigenetic reprogramming such as histone modifications and chromatin reconfigurations established during a previous challenge is the basis for trained immunity. Upon stimulation with the TLR2 ligand $\beta$-glucan, epigenetic profiling of monocyte to macrophage differentiation has been especially revealing in terms of trained immunity signatures (113). 
$\beta$-glucan pre-exposed macrophages produced more inflammatory cytokines such as TNF- $\alpha$ and IL- 6 after a secondary challenge with tripalmitoyl glyceryl cysteine, a TLR2 ligand compared to naive macrophages. In contrast, LPS preexposure induced immune-tolerance in macrophages. Epigenetic marks in the promoter (ACp1) and distal elements (Ace1) of $\mathrm{H} 3 \mathrm{~K} 27 \mathrm{ac}$ were altered by $\beta$-glucan, whereas LPS exposure induced changes in a small subset of the dynamic distal regulatory elements (Ace5) of $\mathrm{H} 3 \mathrm{~K} 27 \mathrm{ac}$. A shift in cellular metabolism is also a key driver of trained immunity, as is the case for $\beta$-glucan trained monocytes, from oxidative phosphorylation to aerobic glycolysis via the mTOR-HIF1 $\alpha$ pathway (114). This metabolic switch may enable rapid cytokine and metabolite production to combat intruding pathogens and is not restricted to glycolysis but also glutaminolysis, accumulation of fumarate (115), the mevalonate pathway and cholesterol synthesis (116).

The paradox that short-lived myeloid lineages (monocytes and DCs) with a turnover of every 5 to 7 days retain trained immunity features lasting several months to years served as a motive for investigating long-lived HSPCs and their potential to be trained (117). Recent studies report trained immunity in HSPCs after acute/chronic stimulation by inflammatory cytokines and pathogen-derived agents, such as LPS, $\beta$-glucan, or BCG (Figure 2A). Relevant epigenetic, metabolic and key signaling pathways that activate or exhaust stem cell activity will be described here (Figure 2B).

$\beta$-glucan stimulation induced expansion of the myeloidbiased $\mathrm{CD}_{4} 1^{+} \mathrm{HSC}$ and MPP subset of the BM that persisted well after transplantation (117). A metabolic shift toward enhanced glycolysis, the mevalonate pathway and cholesterol synthesis in HSPCs was observed. Initial exposure to $\beta$-glucan enhanced the response of HSPCs to a secondary systemic LPS challenge by expansion of the LSK and MPP population and an elevated DNA damage response (lower $\gamma$-H2AX levels) (117). Kaufmann et al., similarly reported cell expansion and enhanced myelopoiesis of BCG-educated HSCs and MPPs in the BM via an IFN- $\gamma$-mediated pathway. These trained HSCs generated epigenetically-modified macrophages with better protection against Mycobacterium tuberculosis infection (118). Primary LPS stimulation likewise elicited trained immunity in HSCs, enabling a faster and more robust response against a secondary Pseudomonas aeruginosa infection (119). Here, a single LPS challenge induced HSC expansion 1 day post injection, which returned to homeostatic levels within 5 days. Transcriptome analysis revealed significant gene expression changes 1 day post injection but a return to normal expression patterns after 4 weeks. Analysis of chromatin opening/closing sites showed
A
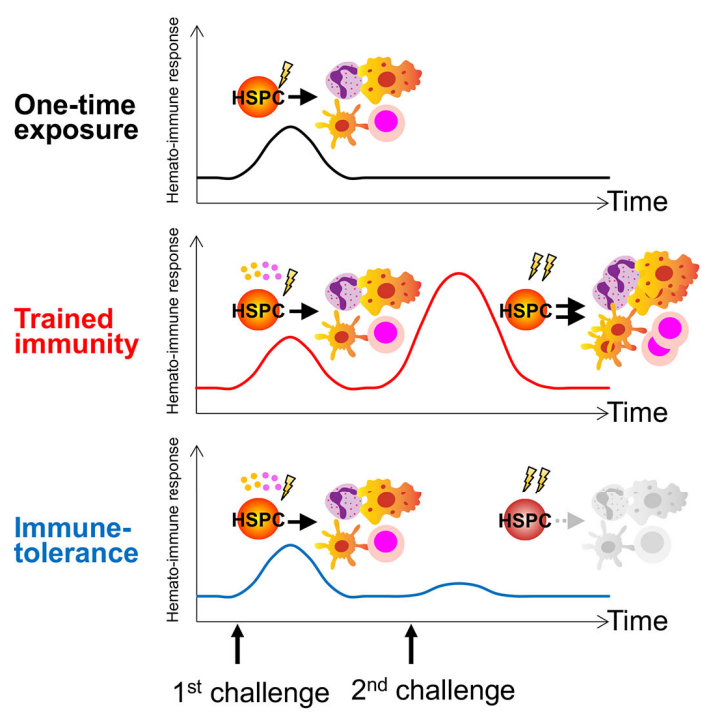

B

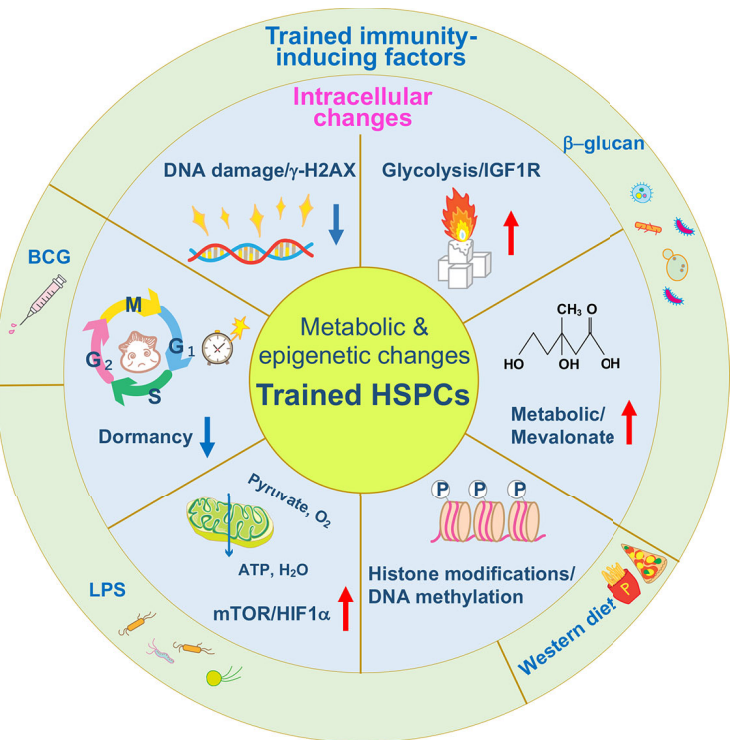

FIGURE 2 | The concept of trained immunity in HSPCs and reported stressors for its induction. (A) A one-time exposure to an immunological challenge drives proliferation and differentiation of HSPCs to enhance host immunity. A primary challenge by innate immune insults such as BCG, $\beta$-glucan or a Western-type diet induces epigenetic or metabolic changes at the cellular level in HSPCs, and activates them directly via cell intrinsic changes or indirectly via cytokine production such as IL-1 $\beta$ and GM-CSF. A secondary challenge such as LPS re-stimulation enhances overall immune response, cytokine production and myelopoiesis (trained immunity). Due to memory formation, HSPCs respond better to a secondary challenge and produce more reactive immune cells that can exert robust immune responses against the infection. A hypothetical scheme of immune-tolerance is shown. Immune-tolerance induces immune suppression upon a secondary challenge, which impairs HSPC function and their potency to differentiate into myeloid cells. As a result, immune responses decline and renders the host more susceptible to infection. (B) The schematic figure summarizes findings published in previous reports and highlights the role of inflammation on trained HSPCs. Several types of inflammation-causing components including $\beta$-glucan, a Western-type diet and BCG affect HSPCs at the intracellular level. These factors induce metabolic and epigenetic changes such as enhanced glycolysis and cholesterol biosynthesis, histone modifications, changes in cell cycle state and an increase in DNA damage. 
newly created open chromatin regions in HSPCs (CD135 LSKs) relevant for the immune response and myeloid differentiation, which were retained 4 weeks post injection. These open chromatin regions were significantly lost in HSCs deficient in TLR4 and C/EBP $\beta$, a mediator of TLR signaling, and demonstrated LPS-TLR4-C/EBP $\beta$-mediated epigenetic memory formation in HSCs (119). Thus, trained immunity confers a protective outcome on HSPCs and ultimately host defense by enhancing the reactivity of mature cells derived from "trained HSPCs" toward a secondary infectious challenge.

Constitutive stimulation by inflammation or infection can also result in immune-tolerance, a state of reduced reactivity (Figure 2A). LPS pre-exposure induced immune-tolerance in monocytes by inactivating epigenetic marks in lipid metabolism and phagocytosis-related genes; these were partially reverted upon $\beta$-glucan stimulation (120). Similarly, BCG vaccination induced $\mathrm{H} 3 \mathrm{~K} 4 \mathrm{me} 3$ activation in human monocytes via the upregulation of IL-1 $\beta$, a key mediator of trained immunity (121). Given that HSPCs chronically stimulated by IL- $1 \beta$ prior to transplantation showed compromised hematopoietic regeneration possibly due to immune-tolerance (34), the induction of trained immunity or immune-tolerance may depend on cell type and/or the duration of the signal, and possibly metabolic adaptability. Recently, a "sterile" Western-type diet was reported to trigger trained immunity in the $\mathrm{Ldlr}^{-/-}$atherosclerosis mouse model through proliferation and functional reprogramming of GMPs into activated and potentially harmful monocytes (122). Hypercholesterolemia reprogramming of HSCs has also been described $(123,124)$. Thus, the relevance of immune-tolerance is readily implicated in chronic inflammatory diseases and possibly for the treatment of certain autoimmune diseases such as type 2 diabetes.

\section{EFFECT OF IMMUNE INSULTS ON HEMATOLOGIC MALIGNANCIES}

Hematopoietic homeostasis is perturbed when the immune system is challenged, such as in cases of infection or inflammation. A systemic increase of inflammatory cytokines and chemokines will stimulate effector immune cells, stromal cells and HSPCs to rapidly replenish consumed innate immune cells at peripheral sites. Stressinduced cell cycle activation of quiescent HSCs will boost hematopoiesis to restore tissue homeostasis, but may come with dire consequences if chronically sustained (i.e., chronic inflammation and autoimmune diseases). Chronic immune stimulation induces cell stress, DNA damage and various hematopoietic dysfunctions, as observed in patients with sickle cell disease often developing myeloid malignancies, possibly from the associated cytokine storm that can cause somatic gene mutations and myeloid neoplasms (125). Persistent cytokine or PAMP stimulation via TNF, IFN, and IL-6 signaling and HSC dysfunction have been well-documented and may readily impact the initiation and progression of hematologic malignancies and BM failure (126).
The risk for developing hematologic malignancies increases exponentially with age (127-129). Although not a hematopoietic challenge per se, aging displays a chronic inflammatory phenotype often associated with expansion of the HSC compartment and lineage-bias toward myeloid and megakaryocytic cells (130). The increase in inflammatory factors, IL-6, IL-1, and C-reactive protein accompanies aging (131) and is basis for the emergence of inflammaging (132). As reported by Mann et al., aged and young HSCs display contrasting responses toward inflammatory stress (133). A myeloid-biased subset, which expands with age and are further marked by CD61 expression shows a poor response to prolonged infectious challenges, and possibly are prone to myeloid leukemia development.

Closely associated with aging is clonal hematopoiesis of indeterminate potential (CHIP), a precursor state where mutations in leukemia-associated driver genes are acquired in individuals with no prior history of hematologic diseases, and thus posing a neoplastic progression risk (134). Somatic genes with high potential to develop into hematopoietic malignancies upon mutation include epigenetic modifiers, splicing factors, proliferation signaling molecules and DNA-damage regulators such as DNMT3A, TET2, ASXL1, JAK2, SF3B1, PPM1D and TP53, all known to be mutated in prominent hematologic malignancies $(135,136)$. Clonal hematopoiesis is a predictor state with adequate potential toward the development of hematologic malignancies (137), while the indeterminate potential aspect of the name reflects the uncertainty behind why only a small population of individuals displaying clonal hematopoiesis develop into full-blown leukemia. Specific mutations may augment inflammation and drive HSC proliferation, while the inflamed environment may further foster genetic ablations in some HSCs and result in their selective expansion. Indeed, several patient studies report of cases where inflammatory conditions promote clonal hematopoiesis (138, 139), and illustrate how HSC impairment upon inflammatory stress may provoke their malignant transformation. This possibility is supported by epidemiological evidence where a history of infection/ autoimmunity strongly correlates with hematologic malignancies $(140,141)$.

A prominent driver mutation in hematological neoplasms is TET2. A recent study reported the abnormal expansion of myeloid cells in Tet2-deficient mice (142). Cull et al., found LPS induced Tet 2 transcription in macrophages, while Tet 2 loss enhanced the secretion of the pro-inflammatory cytokines, IL-6, IL-1 $\beta$, and TNF and the expression of LPS-induced genes associated with an inflammatory state $(143,144)$. This alteration toward an inflammatory environment may favor Tet2-mutant HSPC expansion (145). Interestingly, Meisel et al., reported a breach in the intestinal barrier and subsequent translocation of bacteria result in increased IL-6 production. The risk for development into a pre-leukemic myeloproliferation state was heightened in mice with Tet2-deficinent expression in hematopoietic cells, which was similarly recapitulated in Tet2-deficient germ-free mice upon colitis induction or in response to systemic bacterial stimuli such as treatment with a TLR2-agonist (146). 
This study highlights the requirement for microbialdependent inflammation in the development of preleukemic myeloproliferation.

TLR signaling is also essential for the inflammatory response by shaping HSC fate and blood cell output and if dysregulated, contributes to the loss of HSC potential and/or their malignant transformation (147). Recently, aberrant TLR signaling and its downstream effector molecule, Myd88 has been linked to myelodysplastic syndrome (MDS) and acute myeloid leukemia (148-150). As HSCs express several TLRs enabling their direct stimulation, a causal link between innate immune signaling, HSC dysfunction and hematologic malignancies can be readily imagined, as supported by the following studies. The expression of TLR2 and TLR4 genes was found higher in patients with myelomonocytic and monoblastic acute leukemia (151). Huang et al., reported enhanced innate immune response pathways in chronic myeloid leukemia mouse models (152). MDS patients were found to overexpress TLR1, TLR2, TLR4 and TLR6 in human CD34 ${ }^{+}$cells $(153,154)$. Activation of the NF$\kappa \mathrm{B}$ pathway contributed to HSPC apoptosis in MDS, possibly via a family of Nod-like receptors (NLRs) and inflammatorymediated cell death, or pyroptosis. Particularly, the NLR protein 3 (NLRP3) inflammasome overexpressed in MDS HSPCs increased secretion of IL-1 $\beta$ and IL-18, and caused pyroptotic cell death and eventual cytological dysplasia $(147,155,156)$. An inflamed environment (i.e., chronic inflammation) was found to promote MDS progression by providing MDS HSPCs with a competitive advantage over normal HSPCs. The mechanistic basis for their clonal dominance occurred via a switch from canonical to noncanonical NF- $\mathrm{BB}$ signaling in TLR-TRAF6 primed HSPCs that ultimately sustained myeloid expansion (157). A novel perspective designating the BM niche as the driving force for the initiation and evolution of MDS pathogenesis has been elaborated upon in another review (158) Thus, inflammation is a key determinant for the competitive advantage of MDS HSPCs over normal HSPCs.

Abnormal activation of autoreactive T cells and a shortage in stem cells have been reported in both aplastic anemia (AA) patients and mouse models as the ruling cause of BM failure and appears central to the pathophysiology of acquired AA (159). Increased $\mathrm{CD}^{+}$helper $\mathrm{T}$ cells and activated $\mathrm{CD} 8^{+}$cytotoxic $\mathrm{T}$ cells can be found in the patient's BM and are suspected as culprits in HSPC and BM destruction (160). The CD4 ${ }^{+} \mathrm{T}$ cells dominant in acquired AA secrete IFN- $\gamma$ and TNF- $\alpha$, and have been reported to inhibit $\mathrm{CD}_{3} 4^{+}$colony formation. The adenylate-uridylate-rich element (ARE)-deleted mouse model that constitutively expresses IFN- $\gamma$, revealed IFN $-\gamma$ alone could disrupt CMP generation, prevent hematopoietic differentiation and recapitulate AA pathology (161). Apart from AA, the most often inherited bone marrow failure syndrome, Fanconi anemia is associated with defective DNA repair and genomic instability, which are also primary hallmarks of aging. In addition to pI:C injections, Walter et al., demonstrated the ability of other physiological stimuli (i.e., IFN, G-CSF, TPO or serial bleeding) to cause DNA damage in LT-HSCs in vivo within similar ranges of $\mathrm{pI}$ : , enforce HSC exit out of quiescence, and accelerate failure of the hematopoietic system as observed in Fanconi anemia patients (55). These findings collectively illustrate a causal link between HSC dysfunction induced by chronic immune stimulation and progression toward hematopoietic failure and hematologic malignancies.

\section{DISCUSSION}

Since the initial establishment of the hematopoietic differentiation tree, our understanding of the hematopoietic system, and of the HSC population situated at its apex undergoes continuous refinement. Formerly presumed unresponsive to tissue insult, HSCs in fact show high adaptability under various scenarios and actively cooperate with downstream hematopoietic progenitors, mature cells, and environmental stromal cells as frontline responders to preserve blood homeostasis. However, their ability to respond deftly through self-renewal and differentiation at times brings about detrimental consequences. In this review, we sought to address the latest understanding of HSC biology, in terms of heterogeneity, functionality, and adaptability in steady-state versus perturbed conditions with a particular emphasis on infectious and inflammatory challenges.

From ontogeny to aging, the functional readout of a single HSC in terms of repopulation ability and lineage output differs immensely, leading to the concept of clonality and heterogeneity. Only recently through the development of single-cell approaches can we now address the most basic questions: How many HSCs are born during definitive hematopoiesis formation (162)? Are all HSCs identical in terms of lineage fate $(7,15)$ ? Do all HSCs equally contribute to daily hematopoiesis? Are HSC responses equal under perturbed conditions (133)? The list of questions is ever-expanding. However, transplantation-based studies to test for HSC functionality, where the recipient is subjected to irradiation is a non-physiological setting and should be interpreted with caution as the readout reflects lineage potential enforced on a single HSC rather than its native fate. For example, expanding HSCs after 5-FU treatment contain elevated ROS levels due to high mitochondrial activity but also high repopulating ability (95) and contrasts with steady-state HSCs, where high mitochondrial activity normally implies reduced repopulating ability (96). HSCs can perhaps change their cell fate, depending on the surrounding environment. However, whether this reflects genuine HSC heterogeneity or simply activation of an emergency program remains unresolved. The implementation of new technology to assess lineage output in unperturbed states, such as the inducible sleeping beauty transposon system enabling barcoding of single cells and lineage reconstitution by sequencing $(4,163)$ or the HUE mouse system (164) is beneficial here. Of note, the definition of HSCs (i.e., long-term, short-term and differences amongst the MPP subset) is still ambiguous and their exact contribution to steady-state hematopoiesis remains controversial. Different conclusions may thus be drawn depending on the experimental system at hand and must be examined carefully. 
It is now clear that the BM is not immune-ignorant but a prominent lymphoid organ that receives a large spectrum of hemato-immunological insults. Likewise, BM-residing HSCs are not just quiescent sleeping cells but directly respond to insults not limited to infection, inflammation but also the regeneration of the $\mathrm{BM}$ after toxic agents or irradiation. Depending on the type of DAMPs, PAMPs, cytokines and growth factors involved and the strength/duration of the stimulation, HSCs will alter their fate toward myelopoiesis, granulopoiesis or even bypass progenitors altogether to directly orchestrate on-demand hematopoiesis. HSCs positioned at the interface of perturbed hematopoiesis will execute distinct emergency programs to integrate and fine-tune responses to maintain hematopoietic integrity. However, such beneficial effects of HSC activation can be counteracted by chronic inflammatory conditions. HSC dysfunction upon chronic inflammation or aging as the cause of clonal hematopoiesis and in certain cases leukemic transformation are all readily imaginable scenarios, although direct causality remains to be demonstrated. Emerging reports of trained immunity in HSPCs and mature cells derived from "trained" progenitors with an enhanced protective function provide a novel opportunity for interpretation. The wellestablished immune response against inflammatory or infectious stimuli may have well been under the influence of HSC trained memory and should be revisited. How HSC memory is formed and maintained, and to what degree trained immunity in HSCs dictate host immune defense are areas yet to be explored. Whether the metabolic shift in HSCs induced by memory formation alters the depth of HSC quiescence, population hierarchy and functional heterogeneity, and ultimately clonal hematopoiesis are primary but still unresolved questions. Despite the risk for potential collapse of the hematopoietic system, HSCs nonetheless persist at the frontline not only as an integrative hub for incoming inflammatory signals, but also execute tissue repair in organs beyond the blood system. Trained immune memory in HSCs offers one more additional perspective in elucidating the true nature of HSCs.

In line with this, counterpart immune/stromal niche components also regulate steady-state and stress hematopoiesis. The importance of stromal cells as a major source of HSC maintenance and activation factors for HSC homeostasis is clear. As observed by the apelin ${ }^{+} \mathrm{EC}$ subset tasked to regenerate the BM after irradiation (81), ECs are highly heterogeneous in terms of their identity and function. Other BM constituents, including adipocytes that proliferate and secrete SCF post irradiation to promote BM regeneration (73), certain MSC progenitors that maintain both lymphoid progenitors and HSCs via CXCL12 (165), as well as a subset of regulatory T cells with high CD150 expression that localize in HSC niches and maintain HSC quiescence are additional examples of HSC interaction with immune/ stromal heterogeneity (166). Thus, the heterogeneity of HSCs and their counterpart niche cells become vital when interpreting stressed conditions such as inflammation, infection and the onset of hematologic malignancies. Nonetheless, the bigger question would be, whether this so-called heterogeneity of HSCs (among others) is a distinct population or a continuum where cells retain the ability to transform back and forth. Single-cell RNA-sequencing, despite its immense power offers only a snapshot analysis and may not reflect the true nature of these cells.
Finally, the recently proposed concept of immune memory in HSPCs is a prime topic with clinical relevance. Only several studies till now have demonstrated trained immunity at the level of hematopoietic progenitors via $\beta$-glucan, LPS and BCG, and more can be expected. Besides transcriptional and epigenetic reprogramming and a metabolic shift as key characteristics of trained immunity, much remains to be revealed. For example, the similarities and differences in trained immunity between different stimuli, or whether the formation of a trained memory is mutually exclusive or synergistic. Regarding the duration of trained immunity as well as the cellular/molecular mechanisms associated with it, whether the stability of different signatures, e.g., chromatin modification, histone/DNA methylation, RNA splicing impact the half-life of the memory formed is a primary question among others. Furthermore, what determines whether a cell is able to form a memory? Is memory a privilege granted only to the hematopoietic compartment or do niche/stromal cells possess this ability as well and does this affect their interaction with HSCs? Although yet to be demonstrated, this possibility can readily be imagined as certain stromal cells also take part in the immune response by secreting inflammatory cytokines and chemokines and express PRRs. BCG vaccination induced trained immunity in human monocytes via IL-1 $\beta$ (121), whereas IL-1 $\beta$ re-stimulation damaged the repopulation ability of HSCs post transplantation (34). The latter situation may imply the induction of immune-tolerance, and a possible relevance with aging-associated HSC dysfunction due to IL-1 upregulation observed in the elderly (131). It is important to understand the determinants for dictating trained immunity versus immune-tolerance, and whether the type of stimuli or threshold of signal strength or duration determines the choice for one over the other. Lastly, trained immunity may possibly have detrimental outcomes, as in instances of autoimmune diseases (167), so can HSC memories be a predisposition for future hematopoietic malignancies, say in terms of CHIP progression to MDS? More studies are expected in the near future.

\section{AUTHOR CONTRIBUTIONS}

All authors studied the literature and wrote the manuscript. All authors contributed to the article and approved the submitted version.

\section{FUNDING}

This work was supported in part by KAKENHI from Japan Society for the Promotion of Science (JSPS) (20K17381 to YH, $19 \mathrm{H} 03688$ to TU), KAKETSUKEN (to YH and TU), JSPS fellowship (201820690) and a grant for Excellent Graduate Student at Kumamoto University to MS, and JSPS (18H02843 and 18K19520), The NOVARTIS Foundation, Yasuda Memorial Foundation, and Center for Metabolic Regulation of Healthy Aging at Kumamoto University to HT. 


\section{REFERENCES}

1. Orkin SH, Zon LI. Hematopoiesis: an evolving paradigm for stem cell biology. Cell (2008) 132(4):631-44. doi: 10.1016/j.cell.2008.01.025

2. Jacobsen SEW, Nerlov C. Haematopoiesis in the era of advanced single-cell technologies. Nat Cell Biol (2019) 21(1):2-8. doi: 10.1038/s41556-018-0227-8

3. Busch K, Klapproth K, Barile M, Flossdorf M, Holland-Letz T, Schlenner $\mathrm{SM}$, et al. Fundamental properties of unperturbed haematopoiesis from stem cells in vivo. Nature (2015) 518(7540):542-6. doi: 10.1038/nature14242

4. Sun J, Ramos A, Chapman B, Johnnidis JB, Le L, Ho YJ, et al. Clonal dynamics of native haematopoiesis. Nature (2014) 514(7522):322-7. doi: 10.1038/nature13824

5. Sawai CM, Babovic S, Upadhaya S, Knapp D, Lavin Y, Lau CM, et al. Hematopoietic Stem Cells Are the Major Source of Multilineage Hematopoiesis in Adult Animals. Immunity (2016) 45(3):597-609. doi: 10.1016/j.immuni.2016.08.007

6. Chapple RH, Tseng Y-J, Hu T, Kitano A, Takeichi M, Hoegenauer KA, et al. Lineage tracing of murine adult hematopoietic stem cells reveals active contribution to steady-state hematopoiesis. Blood Adv (2018) 2(11):1220-8. doi: 10.1182/bloodadvances.2018016295

7. Lu R, Czechowicz A, Seita J, Jiang D, Weissman IL. Clonal-level lineage commitment pathways of hematopoietic stem cells in vivo. Proc Natl Acad Sci (2019) 116(4):1447-56. doi: 10.1073/pnas.1801480116

8. Iwasaki H, Arai F, Kubota Y, Dahl M, Suda T. Endothelial protein C receptor-expressing hematopoietic stem cells reside in the perisinusoidal niche in fetal liver. Blood (2010) 116(4):544-53. doi: 10.1182/blood-200908-240903

9. Oguro H, Ding L, Morrison SJ. SLAM family markers resolve functionally distinct subpopulations of hematopoietic stem cells and multipotent progenitors. Cell Stem Cell (2013) 13(1):102-16. doi: 10.1016/j.stem.2013. 05.014

10. Gulati GS, Zukowska M, Noh JJ, Zhang A, Wesche DJ, Sinha R, et al. Neogenin-1 distinguishes between myeloid-biased and balanced Hoxb5 ${ }^{+}$ mouse long-term hematopoietic stem cells. Proc Natl Acad Sci (2019) 116 (50):25115-25. doi: 10.1073/pnas.1911024116

11. Sanjuan-Pla A, Macaulay IC, Jensen CT, Woll PS, Luis TC, Mead A, et al. Platelet-biased stem cells reside at the apex of the haematopoietic stem-cell hierarchy. Nature (2013) 502(7470):232-6. doi: 10.1038/nature12495

12. de Sauvage FJ, Carver-Moore K, Luoh SM, Ryan A, Dowd M, Eaton DL, et al. Physiological regulation of early and late stages of megakaryocytopoiesis by thrombopoietin. J Exp Med (1996) 183(2):651-6. doi: 10.1084/jem.183.2.651

13. Luchsinger LL, de Almeida MJ, Corrigan DJ, Mumau M, Snoeck H-W. Mitofusin 2 maintains haematopoietic stem cells with extensive lymphoid potential. Nature (2016) 529(7587):528-31. doi: 10.1038/nature16500

14. Carrelha J, Meng Y, Kettyle LM, Luis TC, Norfo R, Alcolea V, et al. Hierarchically related lineage-restricted fates of multipotent haematopoietic stem cells. Nature (2018) 554(7690):106-11. doi: 10.1038/ nature25455

15. Rodriguez-Fraticelli AE, Wolock SL, Weinreb CS, Panero R, Patel SH, Jankovic M, et al. Clonal analysis of lineage fate in native haematopoiesis. Nature (2018) 553(7687):212-6. doi: 10.1038/nature25168

16. Haas S, Hansson J, Klimmeck D, Loeffler D, Velten L, Uckelmann H, et al. Inflammation-Induced Emergency Megakaryopoiesis Driven by Hematopoietic Stem Cell-like Megakaryocyte Progenitors. Cell Stem Cell (2015) 17(4):422-34. doi: 10.1016/j.stem.2015.07.007

17. Frisch BJ, Hoffman CM, Latchney SE, LaMere MW, Myers J, Ashton J, et al. Aged marrow macrophages expand platelet-biased hematopoietic stem cells via interleukin-1B. JCI Insight (2019) 4(10). doi: 10.1172/jci.insight.124213

18. Yamamoto R, Wilkinson AC, Nakauchi H. Changing concepts in hematopoietic stem cells. Science (2018) 362(6417):895-6. doi: 10.1126/science.aat7873

19. Mercier FE, Ragu C, Scadden DT. The bone marrow at the crossroads of blood and immunity. Nat Rev Immunol (2012) 12(1):49-60. doi: 10.1038/ nri3132

20. Morrison SJ, Scadden DT. The bone marrow niche for haematopoietic stem cells. Nature (2014) 505(7483):327-34. doi: 10.1038/nature12984

21. Ding L, Saunders TL, Enikolopov G, Morrison SJ. Endothelial and perivascular cells maintain haematopoietic stem cells. Nature (2012) 481 (7382):457-62. doi: 10.1038/nature10783
22. Bruns I, Lucas D, Pinho S, Ahmed J, Lambert MP, Kunisaki Y, et al. Megakaryocytes regulate hematopoietic stem cell quiescence through CXCL4 secretion. Nat Med (2014) 20(11):1315-20. doi: 10.1038/nm.3707

23. Zhao M, Perry JM, Marshall H, Venkatraman A, Qian P, He XC, et al. Megakaryocytes maintain homeostatic quiescence and promote post-injury regeneration of hematopoietic stem cells. Nat Med (2014) 20(11):1321-6. doi: $10.1038 / \mathrm{nm} .3706$

24. Kunisaki Y, Bruns I, Scheiermann C, Ahmed J, Pinho S, Zhang D, et al. Arteriolar niches maintain haematopoietic stem cell quiescence. Nature (2013) 502:637. doi: 10.1038/nature12612

25. Pinho S, Marchand T, Yang E, Wei Q, Nerlov C, Frenette PS. Lineage-Biased Hematopoietic Stem Cells Are Regulated by Distinct Niches. Dev Cell (2018) 44(5):634-41.e4. doi: 10.1016/j.devcel.2018.01.016

26. Cronkite DA, Strutt TM. The Regulation of Inflammation by Innate and Adaptive Lymphocytes. J Immunol Res (2018) 2018:1467538-. doi: 10.1155/ 2018/1467538

27. Essers MA, Offner S, Blanco-Bose WE, Waibler Z, Kalinke U, Duchosal MA, et al. IFNalpha activates dormant haematopoietic stem cells in vivo. Nature (2009) 458(7240):904-8. doi: 10.1038/nature07815

28. Sato T, Onai N, Yoshihara H, Arai F, Suda T, Ohteki T. Interferon regulatory factor-2 protects quiescent hematopoietic stem cells from type I interferondependent exhaustion. Nat Med (2009) 15(6):696-700. doi: 10.1038/nm.1973

29. Pietras EM, Lakshminarasimhan R, Techner JM, Fong S, Flach J, Binnewies $\mathrm{M}$, et al. Re-entry into quiescence protects hematopoietic stem cells from the killing effect of chronic exposure to type I interferons. J Exp Med (2014) 211 (2):245-62. doi: 10.1084/jem.20131043

30. Baldridge MT, King KY, Boles NC, Weksberg DC, Goodell MA. Quiescent haematopoietic stem cells are activated by IFN-gamma in response to chronic infection. Nature (2010) 465(7299):793-7. doi: 10.1038/nature09135

31. de Bruin AM, Demirel O, Hooibrink B, Brandts $\mathrm{CH}$, Nolte MA. Interferongamma impairs proliferation of hematopoietic stem cells in mice. Blood (2013) 121(18):3578-85. doi: 10.1182/blood-2012-05-432906

32. Yamashita M, Passegue E. TNF-alpha Coordinates Hematopoietic Stem Cell Survival and Myeloid Regeneration. Cell Stem Cell (2019) 25(3):357-72.e7. doi: 10.1016/j.stem.2019.05.019

33. Yamazaki S, Ema H, Karlsson G, Yamaguchi T, Miyoshi H, Shioda S, et al. Nonmyelinating Schwann cells maintain hematopoietic stem cell hibernation in the bone marrow niche. Cell (2011) 147(5):1146-58. doi: 10.1016/j.cell.2011.09.053

34. Pietras EM, Mirantes-Barbeito C, Fong S, Loeffler D, Kovtonyuk LV, Zhang S, et al. Chronic interleukin-1 exposure drives haematopoietic stem cells towards precocious myeloid differentiation at the expense of self-renewal. Nat Cell Biol (2016) 18(6):607-18. doi: 10.1038/ncb3346

35. Reynaud D, Pietras E, Barry-Holson K, Mir A, Binnewies M, Jeanne M, et al. IL-6 controls leukemic multipotent progenitor cell fate and contributes to chronic myelogenous leukemia development. Cancer Cell (2011) 20(5):66173. doi: 10.1016/j.ccr.2011.10.012

36. Zhao JL, Ma C, O'Connell RM, Mehta A, DiLoreto R, Heath JR, et al. Conversion of danger signals into cytokine signals by hematopoietic stem and progenitor cells for regulation of stress-induced hematopoiesis. Cell Stem Cell (2014) 14(4):445-59. doi: 10.1016/j.stem.2014.01.007

37. Mossadegh-Keller N, Sarrazin S, Kandalla PK, Espinosa L, Stanley ER, Nutt SL, et al. M-CSF instructs myeloid lineage fate in single haematopoietic stem cells. Nature (2013) 497(7448):239-43. doi: 10.1038/nature12026

38. Takizawa H, Boettcher S, Manz MG. Demand-adapted regulation of early hematopoiesis in infection and inflammation. Blood (2012) 119(13):29913002. doi: 10.1182/blood-2011-12-380113

39. Pietras EM. Inflammation: a key regulator of hematopoietic stem cell fate in health and disease. Blood (2017) 130(15):1693-8. doi: 10.1182/blood-201706-780882

40. Clapes T, Lefkopoulos S, Trompouki E. Stress and Non-Stress Roles of Inflammatory Signals during HSC Emergence and Maintenance. Front Immunol (2016) 7:487. doi: 10.3389/fimmu.2016.00487

41. Decker M, Leslie J, Liu Q, Ding L. Hepatic thrombopoietin is required for bone marrow hematopoietic stem cell maintenance. Science (2018) 360 (6384):106-10. doi: 10.1126/science.aap8861

42. Gabbianelli M, Pelosi E, Montesoro E, Valtieri M, Luchetti L, Samoggia P, et al. Multi-level effects of flt3 ligand on human hematopoiesis: expansion of 
putative stem cells and proliferation of granulomonocytic progenitors/ monocytic precursors. Blood (1995) 86(5):1661-70. doi: 10.1182/ blood.V86.5.1661.bloodjournal8651661

43. Boettcher S, Ziegler P, Schmid MA, Takizawa H, van Rooijen N, Kopf M, et al. Cutting edge: LPS-induced emergency myelopoiesis depends on TLR4expressing nonhematopoietic cells. J Immunol (2012) 188(12):5824-8. doi: 10.4049/jimmunol.1103253

44. Boettcher S, Gerosa RC, Radpour R, Bauer J, Ampenberger F, Heikenwalder M, et al. Endothelial cells translate pathogen signals into G-CSF-driven emergency granulopoiesis. Blood (2014) 124(9):1393-403. doi: 10.1182/blood-2014-04570762

45. Weisbart RH, Golde DW, Clark SC, Wong GG, Gasson JC. Human granulocyte-macrophage colony-stimulating factor is a neutrophil activator. Nature (1985) 314(6009):361-3. doi: 10.1038/314361a0

46. Shi Y, Liu CH, Roberts AI, Das J, Xu G, Ren G, et al. Granulocytemacrophage colony-stimulating factor (GM-CSF) and T-cell responses: what we do and don't know. Cell Res (2006) 16(2):126-33. doi: 10.1038/ sj.cr. 7310017

47. Suda T, Suda J, Ogawa M, Ihle JN. Permissive role of interleukin 3 (IL-3) in proliferation and differentiation of multipotential hemopoietic progenitors in culture. J Cell Physiol (1985) 124(2):182-90. doi: 10.1002/jcp.1041240203

48. Terashima A, Okamoto K, Nakashima T, Akira S, Ikuta K, Takayanagi H. Sepsis-Induced Osteoblast Ablation Causes Immunodeficiency. Immunity (2016) 44(6):1434-43. doi: 10.1016/j.immuni.2016.05.012

49. Honda K, Ohba Y, Yanai H, Negishi H, Mizutani T, Takaoka A, et al. Spatiotemporal regulation of MyD88-IRF-7 signalling for robust type-I interferon induction. Nature (2005) 434(7036):1035-40. doi: 10.1038/ nature 03547

50. Smith JNP, Zhang Y, Li JJ, McCabe A, Jo HJ, Maloney J, et al. Type I IFNs drive hematopoietic stem and progenitor cell collapse via impaired proliferation and increased RIPK1-dependent cell death during shock-like ehrlichial infection. PloS Pathog (2018) 14(8):e1007234. doi: 10.1371/ journal.ppat.1007234

51. La Pine TR, Hill HR. Chapter 151 - Host Defense Mechanisms Against Bacteria. In: RA Polin, WW Fox and SH Abman, editors. Fetal and Neonatal Physiology, 3rd ed. London, UK: W.B. Saunders (2004). p. 1475-86. doi: 10.1016/B978-0-7216-9654-6.50154-5

52. Atzeni F, Sarzi-Puttini P. Tumor Necrosis Factor. In: S Maloy and K Hughes, editors. Brenner's Encyclopedia of Genetics, 2nd ed. San Diego: Academic Press (2013). p. 229-31. doi: 10.1016/B978-0-12-374984-0.01594-1

53. Matatall KA, Jeong M, Chen S, Sun D, Chen F, Mo Q, et al. Chronic Infection Depletes Hematopoietic Stem Cells through Stress-Induced Terminal Differentiation. Cell Rep (2016) 17(10):2584-95. doi: 10.1016/ j.celrep.2016.11.031

54. Takizawa H, Fritsch K, Kovtonyuk LV, Saito Y, Yakkala C, Jacobs K, et al. Pathogen-Induced TLR4-TRIF Innate Immune Signaling in Hematopoietic Stem Cells Promotes Proliferation but Reduces Competitive Fitness. Cell Stem Cell (2017) 21(2):225-40. doi: 10.1016/j.stem.2017.06.013

55. Walter D, Lier A, Geiselhart A, Thalheimer FB, Huntscha S, Sobotta MC, et al. Exit from dormancy provokes DNA-damage-induced attrition in haematopoietic stem cells. Nature (2015) 520(7548):549-52. doi: 10.1038/ nature14131

56. Wang X, Dong F, Zhang S, Yang W, Yu W, Wang Z, et al. TGF-betal Negatively Regulates the Number and Function of Hematopoietic Stem Cells. Stem Cell Rep (2018) 11(1):274-87. doi: 10.1016/j.stemcr.2018.05.017

57. Challen GA, Boles NC, Chambers SM, Goodell MA. Distinct Hematopoietic Stem Cell Subtypes Are Differentially Regulated by TGF- $\beta 1$. Cell Stem Cell (2010) 6(3):265-78. doi: 10.1016/j.stem.2010.02.002

58. Colato RP, Brazão V, do Vale GT, Santello FH, Sampaio PA, Tirapelli CR, et al. Cytokine modulation, oxidative stress and thymic dysfunctions: Role of age-related changes in the experimental Trypanosoma cruzi infection: Agerelated thymic dysfunctions and Trypanosoma cruzi infection. Cytokine (2018) 111:88-96. doi: 10.1016/j.cyto.2018.08.004

59. Beutler BA. TLRs and innate immunity. Blood (2009) 113(7):1399-407. doi: 10.1182/blood-2008-07-019307

60. Nagai Y, Garrett KP, Ohta S, Bahrun U, Kouro T, Akira S, et al. Toll-like receptors on hematopoietic progenitor cells stimulate innate immune system replenishment. Immunity (2006) 24(6):801-12. doi: 10.1016/j.immuni. 2006.04.008

61. Massberg S, Schaerli P, Knezevic-Maramica I, Kollnberger M, Tubo N, Moseman EA, et al. Immunosurveillance by hematopoietic progenitor cells trafficking through blood, lymph, and peripheral tissues. Cell (2007) 131 (5):994-1008. doi: 10.1016/j.cell.2007.09.047

62. Takizawa H, Regoes RR, Boddupalli CS, Bonhoeffer S, Manz MG. Dynamic variation in cycling of hematopoietic stem cells in steady state and inflammation. J Exp Med (2011) 208(2):273-84. doi: 10.1084/jem.20101643

63. Zhao Y, Ling F, Wang HC, Sun XH. Chronic TLR signaling impairs the longterm repopulating potential of hematopoietic stem cells of wild type but not Id 1 deficient mice. PloS One (2013) 8(2):e55552. doi: 10.1371/ journal.pone. 0055552

64. Esplin BL, Shimazu T, Welner RS, Garrett KP, Nie L, Zhang Q, et al. Chronic exposure to a TLR ligand injures hematopoietic stem cells. J Immunol (2011) 186(9):5367-75. doi: 10.4049/jimmunol.1003438

65. Rodriguez S, Chora A, Goumnerov B, Mumaw C, Goebel WS, Fernandez L, et al. Dysfunctional expansion of hematopoietic stem cells and block of myeloid differentiation in lethal sepsis. Blood (2009) 114(19):4064-76. doi: 10.1182/blood-2009-04-214916

66. Scumpia PO, Kelly-Scumpia KM, Delano MJ, Weinstein JS, Cuenca AG, AlQuran S, et al. Cutting edge: bacterial infection induces hematopoietic stem and progenitor cell expansion in the absence of TLR signaling. J Immunol (2010) 184(5):2247-51. doi: 10.4049/jimmunol.0903652

67. Yanez A, Megias J, O’Connor JE, Gozalbo D, Gil ML. Candida albicans induces selective development of macrophages and monocyte derived dendritic cells by a TLR2 dependent signalling. PloS One (2011) 6(9): e24761. doi: 10.1371/journal.pone.0024761

68. Vainieri ML, Blagborough AM, MacLean AL, Haltalli ML, Ruivo N, Fletcher HA, et al. Systematic tracking of altered haematopoiesis during sporozoitemediated malaria development reveals multiple response points. Open Biol (2016) 6(6):1-13. doi: 10.1098/rsob.160038

69. Josefsdottir KS, Baldridge MT, Kadmon CS, King KY. Antibiotics impair murine hematopoiesis by depleting the intestinal microbiota. Blood (2017) 129(6):729-39. doi: 10.1182/blood-2016-03-708594

70. Lee S, Kim H, You G, Kim YM, Lee S, Le VH, et al. Bone marrow CX3CR1+ mononuclear cells relay a systemic microbiota signal to control hematopoietic progenitors in mice. Blood (2019) 134(16):1312-22. doi: 10.1182/blood.2019000495

71. Iwamura C, Bouladoux N, Belkaid Y, Sher A, Jankovic D. Sensing of the microbiota by NOD1 in mesenchymal stromal cells regulates murine hematopoiesis. Blood (2017) 129(2):171-6. doi: 10.1182/blood-2016-06723742

72. Vrakas S, Mountzouris KC, Michalopoulos G, Karamanolis G, Papatheodoridis G, Tzathas C, et al. Intestinal Bacteria Composition and Translocation of Bacteria in Inflammatory Bowel Disease. PloS One (2017) 12(1):e0170034-e. doi: 10.1371/journal.pone.0170034

73. Zhou BO, Yu H, Yue R, Zhao Z, Rios JJ, Naveiras O, et al. Bone marrow adipocytes promote the regeneration of stem cells and haematopoiesis by secreting SCF. Nat Cell Biol (2017) 19(8):891-903. doi: 10.1038/ncb3570

74. Itkin T, Gur-Cohen S, Spencer JA, Schajnovitz A, Ramasamy SK, Kusumbe AP, et al. Distinct bone marrow blood vessels differentially regulate haematopoiesis. Nature (2016) 532(7599):323-8. doi: 10.1038/nature17624

75. Asada N, Katayama Y, Sato M, Minagawa K, Wakahashi K, Kawano H, et al. Matrix-Embedded Osteocytes Regulate Mobilization of Hematopoietic Stem/Progenitor Cells. Cell Stem Cell (2013) 12(6):737-47. doi: 10.1016/ j.stem.2013.05.001

76. Lucas D, Scheiermann C, Chow A, Kunisaki Y, Bruns I, Barrick C, et al. Chemotherapy-induced bone marrow nerve injury impairs hematopoietic regeneration. Nat Med (2013) 19(6):695-703. doi: 10.1038/nm.3155

77. Chow A, Lucas D, Hidalgo A, Méndez-Ferrer S, Hashimoto D, Scheiermann C, et al. Bone marrow $\mathrm{CD} 169+$ macrophages promote the retention of hematopoietic stem and progenitor cells in the mesenchymal stem cell niche. J Exp Med (2011) 208(2):261-71. doi: 10.1084/jem.20101688

78. Tikhonova AN, Dolgalev I, Hu H, Sivaraj KK, Hoxha E, Cuesta-Domínguez Á, et al. The bone marrow microenvironment at single-cell resolution. Nature (2019) 569(7755):222-8. doi: 10.1038/s41586-019-1104-8 
79. Abbuehl JP, Tatarova Z, Held W, Huelsken J. Long-Term Engraftment of Primary Bone Marrow Stromal Cells Repairs Niche Damage and Improves Hematopoietic Stem Cell Transplantation. Cell Stem Cell (2017) 21(2):24155.e6. doi: 10.1016/j.stem.2017.07.004

80. Guo P, Poulos MG, Palikuqi B, Badwe CR, Lis R, Kunar B, et al. Endothelial jagged-2 sustains hematopoietic stem and progenitor reconstitution after myelosuppression. J Clin Invest (2017) 127(12):4242-56. doi: 10.1172/ JCI92309

81. Chen Q, Liu Y, Jeong HW, Stehling M, Dinh VV, Zhou B, et al. Apelin(+) Endothelial Niche Cells Control Hematopoiesis and Mediate Vascular Regeneration after Myeloablative Injury. Cell Stem Cell (2019) 25(6):76883.e6. doi: 10.1016/j.stem.2019.10.006

82. Yanez A, Hassanzadeh-Kiabi N, Ng MY, Megias J, Subramanian A, Liu GY, et al. Detection of a TLR2 agonist by hematopoietic stem and progenitor cells impacts the function of the macrophages they produce. Eur J Immunol (2013) 43(8):2114-25. doi: 10.1002/eji.201343403

83. Schmid MA, Takizawa H, Baumjohann DR, Saito Y, Manz MG. Bone marrow dendritic cell progenitors sense pathogens via Toll-like receptors and subsequently migrate to inflamed lymph nodes. Blood (2011) 118 (18):4829-40. doi: 10.1182/blood-2011-03-344960

84. Burberry A, Zeng MY, Ding L, Wicks I, Inohara N, Morrison SJ, et al. Infection mobilizes hematopoietic stem cells through cooperative NOD-like receptor and Toll-like receptor signaling. Cell host Microbe (2014) 15 (6):779-91. doi: 10.1016/j.chom.2014.05.004

85. Vandoorne K, Rohde D, Kim HY, Courties G, Wojtkiewicz G, Honold L, et al. Imaging the Vascular Bone Marrow Niche During Inflammatory Stress. Circ Res (2018) 123(4):415-27. doi: 10.1161/CIRCRESAHA.118.313302

86. Mitroulis I, Chen LS, Singh RP, Kourtzelis I, Economopoulou M, Kajikawa T, et al. Secreted protein Del-1 regulates myelopoiesis in the hematopoietic stem cell niche. J Clin Invest (2017) 127(10):3624-39. doi: 10.1172/JCI92571

87. MacLean AL, Smith MA, Liepe J, Sim A, Khorshed R, Rashidi NM, et al. Single Cell Phenotyping Reveals Heterogeneity Among Hematopoietic Stem Cells Following Infection. Stem Cells (2017) 35(11):2292-304. doi: 10.1002/ stem.2692

88. Behzadi Fard M, Kaviani S, Atashi A. Parvovirus B19 Infection in Human Bone Marrow Mesenchymal Stem Cells Affects Gene Expression of IL-6 and TNF- $\alpha$ and also Affects Hematopoietic Stem Cells Differentiation. Indian J Hematol Blood Transfus (2019) 35(4):765-72. doi: 10.1007/s12288-01901097-7

89. Prendergast ÁM, Kuck A, van Essen M, Haas S, Blaszkiewicz S, Essers MA. IFN $\alpha$-mediated remodeling of endothelial cells in the bone marrow niche. Haematologica (2017) 102(3):445-53. doi: 10.3324/haematol.2016.151209

90. Heissig B, Hattori K, Dias S, Friedrich M, Ferris B, Hackett NR, et al. Recruitment of stem and progenitor cells from the bone marrow niche requires MMP-9 mediated release of kit-ligand. Cell (2002) 109(5):625-37. doi: 10.1016/S0092-8674(02)00754-7

91. de Graaf CA, Kauppi M, Baldwin T, D. Hyland C, Metcalf D, Willson TA, et al. Regulation of hematopoietic stem cells by their mature progeny. Proc Natl Acad Sci (2010) 107(50):21689-94. doi: 10.1073/pnas.1016166108

92. Hérodin F, Bourin P, Mayol JF, Lataillade JJ, Drouet M. Short-term injection of antiapoptotic cytokine combinations soon after lethal gamma -irradiation promotes survival. Blood (2003) 101(7):2609-16. doi: 10.1182/blood-200206-1634

93. Logan RM, Stringer AM, Bowen JM, Gibson RJ, Sonis ST, Keefe DM. Serum levels of NFkappaB and pro-inflammatory cytokines following administration of mucotoxic drugs. Cancer Biol Ther (2008) 7(7):1139-45. doi: 10.4161/cbt.7.7.6207

94. Di Maggio FM, Minafra L, Forte GI, Cammarata FP, Lio D, Messa C, et al. Portrait of inflammatory response to ionizing radiation treatment. J Inflammation (2015) 12(1):14. doi: 10.1186/s12950-015-0058-3

95. Umemoto T, Hashimoto M, Matsumura T, Nakamura-Ishizu A, Suda T. Ca2+-mitochondria axis drives cell division in hematopoietic stem cells. J Exp Med (2018) 215(8):2097-113. doi: 10.1084/jem.20180421

96. Ito K, Hirao A, Arai F, Matsuoka S, Takubo K, Hamaguchi I, et al. Regulation of oxidative stress by ATM is required for self-renewal of haematopoietic stem cells. Nature (2004) 431(7011):997-1002. doi: 10.1038/nature02989

97. Vannini N, Girotra M, Naveiras O, Nikitin G, Campos V, Giger S, et al. Specification of haematopoietic stem cell fate via modulation of mitochondrial activity. Nat Commun (2016) 7(1):13125. doi: 10.1038/ ncomms 13125

98. Nakamura-Ishizu A, Matsumura T, Stumpf PS, Umemoto T, Takizawa H, Takihara Y, et al. Thrombopoietin Metabolically Primes Hematopoietic Stem Cells to Megakaryocyte-Lineage Differentiation. Cell Rep (2018) 25 (7):1772-85.e6. doi: 10.1016/j.celrep.2018.10.059

99. Guo L, Rondina MT. The Era of Thromboinflammation: Platelets Are Dynamic Sensors and Effector Cells During Infectious Diseases. Front Immunol (2019) 10:2204. doi: 10.3389/fimmu.2019.02204

100. Jenne Craig N, Wong Connie HY, Zemp Franz J, McDonald B, Rahman Masmudur M, Forsyth Peter A, et al. Neutrophils Recruited to Sites of Infection Protect from Virus Challenge by Releasing Neutrophil Extracellular Traps. Cell host Microbe (2013) 13(2):169-80. doi: 10.1016/ j.chom.2013.01.005

101. Han ZC, Lu M, Li J, Defard M, Boval B, Schlegel N, et al. Platelet Factor 4 and Other CXC Chemokines Support the Survival of Normal Hematopoietic Cells and Reduce the Chemosensitivity of Cells to Cytotoxic Agents. Blood (1997) 89(7):2328-35. doi: 10.1182/blood.V89.7.2328

102. Olson TS, Caselli A, Otsuru S, Hofmann TJ, Williams R, Paolucci P, et al. Megakaryocytes promote murine osteoblastic HSC niche expansion and stem cell engraftment after radioablative conditioning. Blood (2013) 121 (26):5238-49. doi: 10.1182/blood-2012-10-463414

103. Arai F, Hirao A, Ohmura M, Sato H, Matsuoka S, Takubo K, et al. Tie2/ Angiopoietin-1 Signaling Regulates Hematopoietic Stem Cell Quiescence in the Bone Marrow Niche. Cell (2004) 118(2):149-61. doi: 10.1016/j.cell.2004.07.004

104. Zhou BO, Ding L, Morrison SJ. Hematopoietic stem and progenitor cells regulate the regeneration of their niche by secreting Angiopoietin-1. Elife (2015) 4:e05521-e. doi: 10.7554/eLife.05521

105. DiMascio L, Voermans C, Uqoezwa M, Duncan A, Lu D, Wu J, et al. Identification of Adiponectin as a Novel Hemopoietic Stem Cell Growth Factor. J Immunol (2007) 178(6):3511-20. doi: 10.4049/jimmunol.178.6.3511

106. Cuminetti V, Arranz L. Bone Marrow Adipocytes: The Enigmatic Components of the Hematopoietic Stem Cell Niche. J Clin Med (2019) 8 (5):707. doi: 10.3390/jcm8050707

107. Severe N, Karabacak NM, Gustafsson K, Baryawno N, Courties G, Kfoury Y, et al. Stress-Induced Changes in Bone Marrow Stromal Cell Populations Revealed through Single-Cell Protein Expression Mapping. Cell Stem Cell (2019) 25(4):570-83.e7. doi: 10.1016/j.stem.2019.06.003

108. Yin X, Hu L, Zhang Y, Zhu C, Cheng H, Xie X, et al. PDGFB-expressing mesenchymal stem cells improve human hematopoietic stem cell engraftment in immunodeficient mice. Bone Marrow Transplant (2020) 55 (6):1029-40. doi: 10.1038/s41409-019-0766-z

109. Hua W-K, Qi J, Cai Q, Carnahan E, Ayala Ramirez M, Li L, et al. HDAC8 regulates long-term hematopoietic stem-cell maintenance under stress by modulating p53 activity. Blood (2017) 130(24):2619-30. doi: 10.1182/blood2017-03-771386

110. Chen Y, Ma X, Zhang M, Wang X, Wang C, Wang H, et al. Gadd45a regulates hematopoietic stem cell stress responses in mice. Blood (2014) 123 (6):851-62. doi: 10.1182/blood-2013-05-504084

111. Khattar E, Maung KZY, Chew CL, Ghosh A, Mok MMH, Lee P, et al. Rap1 regulates hematopoietic stem cell survival and affects oncogenesis and response to chemotherapy. Nat Commun (2019) 10(1):5349. doi: 10.1038/ s41467-019-13082-9

112. Netea MG, Joosten LA, Latz E, Mills KH, Natoli G, Stunnenberg HG, et al. Trained immunity: A program of innate immune memory in health and disease. Science (2016) 352(6284):aaf1098. doi: 10.1126/science.aaf1098

113. Saeed S, Quintin J, Kerstens HH, Rao NA, Aghajanirefah A, Matarese F, et al. Epigenetic programming of monocyte-to-macrophage differentiation and trained innate immunity. Science (2014) 345(6204):1251086. doi: 10.1126/ science. 1251086

114. Cheng SC, Quintin J, Cramer RA, Shepardson KM, Saeed S, Kumar V, et al. mTOR- and HIF-1 $\alpha$-mediated aerobic glycolysis as metabolic basis for trained immunity. Science (2014) 345(6204):1250684. doi: 10.1126/ science. 1250684

115. Arts RJ, Novakovic B, Ter Horst R, Carvalho A, Bekkering S, Lachmandas E, et al. Glutaminolysis and Fumarate Accumulation Integrate Immunometabolic and Epigenetic Programs in Trained Immunity. Cell Metab (2016) 24(6):807-19. doi: 10.1016/j.cmet.2016.10.008 
116. Bekkering S, Arts RJW, Novakovic B, Kourtzelis I, van der Heijden C, Li Y, et al. Metabolic Induction of Trained Immunity through the Mevalonate Pathway. Cell (2018) 172(1-2):135-46.e9. doi: 10.1016/j.cell.2017.11.025

117. Mitroulis I, Ruppova K, Wang B, Chen LS, Grzybek M, Grinenko T, et al. Modulation of Myelopoiesis Progenitors Is an Integral Component of Trained Immunity. Cell (2018) 172(1-2):147-61 e12. doi: 10.1016/ j.cell.2017.11.034

118. Kaufmann E, Sanz J, Dunn JL, Khan N, Mendonca LE, Pacis A, et al. BCG Educates Hematopoietic Stem Cells to Generate Protective Innate Immunity against Tuberculosis. Cell (2018) 172(1-2):176-90.e19. doi: 10.1016/ j.cell.2017.12.031

119. de Laval B, Maurizio J, Kandalla PK, Brisou G, Simonnet L, Huber C, et al. C/EBP $\beta$-Dependent Epigenetic Memory Induces Trained Immunity in Hematopoietic Stem Cells. Cell Stem Cell (2020) 26(5):657-74.e8. doi: 10.1016/j.stem.2020.01.017

120. Novakovic B, Habibi E, Wang SY, Arts RJW, Davar R, Megchelenbrink W, et al. $\beta$-Glucan Reverses the Epigenetic State of LPS-Induced Immunological Tolerance. Cell (2016) 167(5):1354-68.e14. doi: 10.1016/j.cell.2016.09.034

121. Arts RJW, Moorlag S, Novakovic B, Li Y, Wang SY, Oosting M, et al. BCG Vaccination Protects against Experimental Viral Infection in Humans through the Induction of Cytokines Associated with Trained Immunity. Cell host Microbe (2018) 23(1):89-100.e5. doi: 10.1016/j.chom.2017.12.010

122. Christ A, Gunther P, Lauterbach MAR, Duewell P, Biswas D, Pelka K, et al. Western Diet Triggers NLRP3-Dependent Innate Immune Reprogramming. Cell (2018) 172(1-2):162-75.e14. doi: 10.1016/j.cell.2017.12.013

123. Seijkens T, Hoeksema MA, Beckers L, Smeets E, Meiler S, Levels J, et al. Hypercholesterolemia-induced priming of hematopoietic stem and progenitor cells aggravates atherosclerosis. FASEB J (2014) 28(5):2202-13. doi: 10.1096/fj.13-243105

124. van Kampen E, Jaminon A, van Berkel TJ, Van Eck M. Diet-induced (epigenetic) changes in bone marrow augment atherosclerosis. J Leukoc Biol (2014) 96(5):833-41. doi: 10.1189/jlb.1A0114-017R

125. Li Y, Maule J, Neff JL, McCall CM, Rapisardo S, Lagoo AS, et al. Myeloid neoplasms in the setting of sickle cell disease: an intrinsic association with the underlying condition rather than a coincidence; report of 4 cases and review of the literature. Mod Pathol (2019) 32(12):1712-26. doi: 10.1038/s41379019-0325-6

126. Trompouki E, Mullen L, Fernandez-Reyes D, Yodoi J, Kim S, Schuettpelz LG. Editorial: Inflammatory Signaling in Bone Marrow Failure and Hematopoietic Malignancy. Front Immunol (2017) 8(660):1-2. doi: 10.3389/fimmu.2017.00660

127. Khwaja A, Bjorkholm M, Gale RE, Levine RL, Jordan CT, Ehninger G, et al. Acute myeloid leukaemia. Nat Rev Dis Primers (2016) 2:16010. doi: 10.1038/ nrdp.2016.10

128. Neukirchen J, Schoonen WM, Strupp C, Gattermann N, Aul C, Haas R, et al. Incidence and prevalence of myelodysplastic syndromes: data from the Düsseldorf MDS-registry. Leuk Res (2011) 35(12):1591-6. doi: 10.1016/ j.leukres.2011.06.001

129. Hallek M, Shanafelt TD, Eichhorst B. Chronic lymphocytic leukaemia. Lancet (London England) (2018) 391(10129):1524-37. doi: 10.1016/S01406736(18)30422-7

130. Cho RH, Sieburg HB, Muller-Sieburg CE. A new mechanism for the aging of hematopoietic stem cells: aging changes the clonal composition of the stem cell compartment but not individual stem cells. Blood (2008) 111(12):555361. doi: 10.1182/blood-2007-11-123547

131. Ferrucci L, Corsi A, Lauretani F, Bandinelli S, Bartali B, Taub DD, et al. The origins of age-related proinflammatory state. Blood (2005) 105(6):2294-9. doi: 10.1182/blood-2004-07-2599

132. Kovtonyuk LV, Fritsch K, Feng X, Manz MG, Takizawa H. Inflamm-Aging of Hematopoiesis, Hematopoietic Stem Cells, and the Bone Marrow Microenvironment. Front Immunol (2016) 7:502. doi: 10.3389/ fimmu.2016.00502

133. Mann M, Mehta A, de Boer CG, Kowalczyk MS, Lee K, Haldeman P, et al. Heterogeneous Responses of Hematopoietic Stem Cells to Inflammatory Stimuli Are Altered with Age. Cell Rep (2018) 25(11):2992-3005.e5. doi: 10.1016/j.celrep.2018.11.056

134. Steensma DP, Bejar R, Jaiswal S, Lindsley RC, Sekeres MA, Hasserjian RP, et al. Clonal hematopoiesis of indeterminate potential and its distinction from myelodysplastic syndromes. Blood (2015) 126(1):9-16. doi: 10.1182/ blood-2015-03-631747

135. Jaiswal S, Fontanillas P, Flannick J, Manning A, Grauman PV, Mar BG, et al. Age-related clonal hematopoiesis associated with adverse outcomes. $N$ Engl J Med (2014) 371(26):2488-98. doi: 10.1056/NEJMoa1408617

136. Genovese G, Kähler AK, Handsaker RE, Lindberg J, Rose SA, Bakhoum SF, et al. Clonal hematopoiesis and blood-cancer risk inferred from blood DNA sequence. N Engl J Med (2014) 371(26):2477-87. doi: 10.1056/ NEJMoa1409405

137. Jaiswal S, Fontanillas P, Flannick J, Manning A, Grauman PV, Mar BG, et al. Age-Related Clonal Hematopoiesis Associated with Adverse Outcomes. N Engl J Med (2014) 371(26):2488-98. doi: 10.1056/NEJMoa1408617

138. Yoshizato T, Dumitriu B, Hosokawa K, Makishima H, Yoshida K, Townsley D, et al. Somatic Mutations and Clonal Hematopoiesis in Aplastic Anemia. N Engl J Med (2015) 373(1):35-47. doi: 10.1056/NEJMoa 1414799

139. Zhang CRC, Nix D, Gregory M, Ciorba MA, Ostrander EL, Newberry RD, et al. Inflammatory cytokines promote clonal hematopoiesis with specific mutations in ulcerative colitis patients. Exp Hematol (2019) 80:36-41.e3. doi: 10.1016/j.exphem.2019.11.008

140. Kristinsson SY, Björkholm M, Hultcrantz M, Derolf ÅR, Landgren O, Goldin LR. Chronic immune stimulation might act as a trigger for the development of acute myeloid leukemia or myelodysplastic syndromes. J Clin Oncol (2011) 29(21):2897-903. doi: 10.1200/JCO.2011.34.8540

141. Kristinsson SY, Landgren O, Samuelsson J, Björkholm M, Goldin LR. Autoimmunity and the risk of myeloproliferative neoplasms. Haematologica (2010) 95(7):1216-20. doi: 10.3324/haematol.2009.020412

142. Moran-Crusio K, Reavie L, Shih A, Abdel-Wahab O, Ndiaye-Lobry D, Lobry C, et al. Tet2 loss leads to increased hematopoietic stem cell self-renewal and myeloid transformation. Cancer Cell (2011) 20(1):11-24. doi: 10.1016/ j.ccr.2011.06.001

143. Zhang Q, Zhao K, Shen Q, Han Y, Gu Y, Li X, et al. Tet2 is required to resolve inflammation by recruiting Hdac2 to specifically repress IL-6. Nature (2015) 525(7569):389-93. doi: 10.1038/nature15252

144. Cull AH, Snetsinger B, Buckstein R, Wells RA, Rauh MJ. Tet2 restrains inflammatory gene expression in macrophages. Exp Hematol (2017) 55:5670.e13. doi: 10.1016/j.exphem.2017.08.001

145. Abegunde SO, Buckstein R, Wells RA, Rauh MJ. An inflammatory environment containing TNF $\alpha$ favors Tet2-mutant clonal hematopoiesis. Exp Hematol (2018) 59:60-5. doi: 10.1016/j.exphem.2017.11.002

146. Meisel M, Hinterleitner R, Pacis A, Chen L, Earley ZM, Mayassi T, et al. Microbial signals drive pre-leukaemic myeloproliferation in a Tet2-deficient host. Nature (2018) 557(7706):580-4. doi: 10.1038/s41586-018-0125-Z

147. Barreyro L, Chlon TM, Starczynowski DT. Chronic immune response dysregulation in MDS pathogenesis. Blood (2018) 132(15):1553-60. doi: 10.1182/blood-2018-03-784116

148. Wang JQ, Jeelall YS, Beutler B, Horikawa K, Goodnow CC. Consequences of the recurrent MYD88(L265P) somatic mutation for B cell tolerance. J Exp Med (2014) 211(3):413-26. doi: 10.1084/jem.20131424

149. Cannova J, Breslin SJP, Zhang J. Toll-like receptor signaling in hematopoietic homeostasis and the pathogenesis of hematologic diseases. Front Med (2015) 9(3):288-303. doi: 10.1007/s11684-015-0412-0

150. Monlish DA, Bhatt ST, Schuettpelz LG. The Role of Toll-Like Receptors in Hematopoietic Malignancies. Front Immunol (2016) 7(390):1-12. doi: 10.3389/fimmu.2016.00390

151. Rybka J, Butrym A, Wróbel T, Jaźwiec B, Stefanko E, Dobrzyńska O, et al. The expression of Toll-like receptors in patients with acute myeloid leukemia treated with induction chemotherapy. Leuk Res (2015) 39(3):318-22. doi: 10.1016/j.leukres.2015.01.002

152. Huang W, Liu B, Eklund EA. Investigating the role of the innate immune response in relapse or blast crisis in chronic myeloid leukemia. Leukemia (2020) 34:2364-74. doi: 10.1038/s41375-020-0771-7

153. Maratheftis CI, Andreakos E, Moutsopoulos HM, Voulgarelis M. Toll-like receptor-4 is up-regulated in hematopoietic progenitor cells and contributes to increased apoptosis in myelodysplastic syndromes. Clin Cancer Res (2007) 13(4):1154-60. doi: 10.1158/1078-0432.CCR-06-2108

154. Wei Y, Dimicoli S, Bueso-Ramos C, Chen R, Yang H, Neuberg D, et al. Tolllike receptor alterations in myelodysplastic syndrome. Leukemia (2013) 27 (9):1832-40. doi: 10.1038/leu.2013.180 
155. Basiorka AA, McGraw KL, Eksioglu EA, Chen X, Johnson J, Zhang L, et al. The NLRP3 inflammasome functions as a driver of the myelodysplastic syndrome phenotype. Blood (2016) 128(25):2960-75. doi: 10.1182/blood2016-07-730556

156. Sallman DA, Cluzeau T, Basiorka AA, List A. Unraveling the Pathogenesis of MDS: The NLRP3 Inflammasome and Pyroptosis Drive the MDS Phenotype. Front Oncol (2016) 6:151-. doi: 10.3389/fonc.2016.00151

157. Muto T, Walker CS, Choi K, Hueneman K, Smith MA, Gul Z, et al. Adaptive response to inflammation contributes to sustained myelopoiesis and confers a competitive advantage in myelodysplastic syndrome HSCs. Nat Immunol (2020) 21(5):535-45. doi: 10.1038/s41590-020-0663-z

158. Pronk E, Raaijmakers MHGP. The mesenchymal niche in MDS. Blood (2019) 133(10):1031-8. doi: 10.1182/blood-2018-10-844639

159. Young NS, Calado RT, Scheinberg P. Current concepts in the pathophysiology and treatment of aplastic anemia. Blood (2006) 108 (8):2509-19. doi: 10.1182/blood-2006-03-010777

160. Luzzatto L, Risitano AM. Advances in understanding the pathogenesis of acquired aplastic anaemia. Br J Haematol (2018) 182(6):758-76. doi: 10.1111/bjh.15443

161. Lin F-c, Karwan M, Saleh B, Hodge DL, Chan T, Boelte KC, et al. IFN- $\gamma$ causes aplastic anemia by altering hematopoietic stem/progenitor cell composition and disrupting lineage differentiation. Blood (2014) 124 (25):3699-708. doi: 10.1182/blood-2014-01-549527

162. Henninger J, Santoso B, Hans S, Durand E, Moore J, Mosimann C, et al. Clonal fate mapping quantifies the number of haematopoietic stem cells that arise during development. Nat Cell Biol (2017) 19(1):17-27. doi: 10.1038/ ncb3444
163. Pei W, Feyerabend TB, Rössler J, Wang X, Postrach D, Busch K, et al. Polylox barcoding reveals haematopoietic stem cell fates realized in vivo. Nature (2017) 548(7668):456-60. doi: 10.1038/nature23653

164. Yu VWC, Yusuf RZ, Oki T, Wu J, Saez B, Wang X, et al. Epigenetic Memory Underlies Cell-Autonomous Heterogeneous Behavior of Hematopoietic Stem Cells. Cell (2017) 168(5):944-5. doi: 10.1016/j.cell.2017.02.010

165. Greenbaum A, Hsu YM, Day RB, Schuettpelz LG, Christopher MJ, Borgerding JN, et al. CXCL12 in early mesenchymal progenitors is required for haematopoietic stem-cell maintenance. Nature (2013) 495 (7440):227-30. doi: 10.1038/nature11926

166. Fujisaki J, Wu J, Carlson AL, Silberstein L, Putheti P, Larocca R, et al. In vivo imaging of Treg cells providing immune privilege to the haematopoietic stem-cell niche. Nature (2011) 474(7350):216-9. doi: 10.1038/nature10160

167. Arts RJW, Joosten LAB, Netea MG. The Potential Role of Trained Immunity in Autoimmune and Autoinflammatory Disorders. Front Immunol (2018) 9:298-. doi: 10.3389/fimmu.2018.00298

Conflict of Interest: The authors declare that the research was conducted in the absence of any commercial or financial relationships that could be construed as a potential conflict of interest.

Copyright (C) 2020 Sezaki, Hayashi, Wang, Johansson, Umemoto and Takizawa. This is an open-access article distributed under the terms of the Creative Commons Attribution License (CC BY). The use, distribution or reproduction in other forums is permitted, provided the original author(s) and the copyright owner(s) are credited and that the original publication in this journal is cited, in accordance with accepted academic practice. No use, distribution or reproduction is permitted which does not comply with these terms. 